Full length article

\title{
Thermal stability and mechanical properties of sputtered (Hf,Ta,V,W,Zr)-diborides
}

\author{
A. Kirnbauer ${ }^{a, *}$, A. Wagner ${ }^{a}$, V. Moraes ${ }^{a}$, D. Primetzhofer ${ }^{b}$, M. Hans ${ }^{c}$, J.M. Schneider ${ }^{c}$, \\ P. Polcik ${ }^{\mathrm{d}}$, P.H. Mayrhofer ${ }^{\mathrm{a}}$
}

a Institute of Materials Science and Technology, TU Wien, 1060 Vienna, Austria

${ }^{\mathrm{b}}$ Department of Physics and Astronomy, Uppsala University, 75120 Uppsala, Sweden

${ }^{c}$ Materials Chemistry, RWTH Aachen University, 52074 Aachen, Germany

d Plansee Composite Materials GmbH, 86983 Lechbruck am See, Germany

\section{A R T I C L E I N F O}

\section{Article history:}

Received 23 July 2020

Revised 29 August 2020

Accepted 5 September 2020

Available online 10 September 2020

\section{Keywords:}

High-entropy alloys (HEAs)

Magnetron sputtering

multi-element diborides

Thermal stability

High-entropy sublattice (HES)

\begin{abstract}
A B S T R A C T
Non-reactive magnetron sputtering of a diboride target composed of $\mathrm{HfB}_{2}, \mathrm{TaB}_{2}, \mathrm{VB}_{2}, \mathrm{~W}_{2} \mathrm{~B}_{5}$, and $\mathrm{ZrB}$. with equimolar composition leads to the formation of crystalline single-phase solid solution diboride thin films, (Hf,Ta,V,W,Zr)B $\mathrm{B}_{2}$, with a high-entropy metal-sublattice. Their growth morphology (dense and finefibrous), crystal structure ( $\mathrm{AlB}_{2}$-type), as well as mechanical properties (indentation modulus $\mathrm{E}$ of $\sim 580$ GPa and hardness $\mathrm{H}$ of $45 \mathrm{GPa}$ ), and chemical compositions are basically independent of the substrate bias potential applied (varied between -40 and $-100 \mathrm{~V}$ ) during the deposition at $450^{\circ} \mathrm{C}$

Detailed X-ray diffraction (XRD) and atom probe tomography (APT) studies indicate that the $(\mathrm{Hf}, \mathrm{Ta}, \mathrm{V}, \mathrm{W}, \mathrm{Zr}) \mathrm{B}_{2}$ thin films remain single-phase $\mathrm{AlB}_{2}$-structured (with randomly distributed elements at the metal-sublattice) during vacuum-annealing at temperatures up to $1200^{\circ} \mathrm{C}$. Only when increasing the annealing temperature to $1400^{\circ} \mathrm{C}$, the formation of small orthorhombic structured $(\mathrm{V}, \mathrm{W}) \mathrm{B}$-based regions can be detected, indicating the onset of decomposition of ( $\mathrm{Hf}, \mathrm{Ta}, \mathrm{V}, \mathrm{W}, \mathrm{Zr}) \mathrm{B}_{2}$ thin films into ( $\left.\mathrm{Hf}, \mathrm{Ta}, \mathrm{Zr}\right) \mathrm{B}_{2}$ and $(\mathrm{V}, \mathrm{W}) \mathrm{B}$, accompanied by the formation of confined B-rich boundary regions between these phases. After annealing at $1400^{\circ} \mathrm{C}$ the hardness is still very high with $44 \mathrm{GPa}$, as the volume fraction of the newly formed $(\mathrm{V}, \mathrm{W}) \mathrm{B}$-rich domains is small and the majority of the coating is still solid-solution (Hf,Ta,V,W,Zr)B $B_{2}$ with severe lattice distortions. Only at even higher $\mathrm{T}_{\mathrm{a}}$ of 1500 and $1600{ }^{\circ} \mathrm{C}, \mathrm{H}$ decreased to $39 \mathrm{GPa}$.
\end{abstract}

(c) 2020 Acta Materialia Inc. Published by Elsevier Ltd. This is an open access article under the CC BY-NC-ND license (http://creativecommons.org/licenses/by-nc-nd/4.0/)

\section{Introduction}

The demand for materials able to withstand high temperatures and mechanical loads is connected with new technological developments. Therefore, these are in focus of many research activities. The development of protective thin film materials has the advantage of combining basic materials science concepts with the huge and versatile variety in process conditions accessible through physical vapour deposition (like magnetron sputtering). A relatively new alloying concept - equiatomic multicomponent alloys with at least five principal elements - was introduced by Cantor in 2004 [1]. As these alloys exhibit a configurational entropy $\Delta S_{\text {conf }}$ of $>$

\footnotetext{
* Corresponding author.

E-mail address: alexander.kirnbauer@tuwien.ac.at (A. Kirnbauer).
}

$1.5 \cdot R$, with $R$ being the universal gas constant, the term highentropy alloys (HEA) was introduced by Yeh et al. [2] also in 2004.

In addition to HEAs a corresponding high-entropy concept has also been applied to ceramic materials including borides, carbides, and oxides. According to Murty, Yeh, and Ranganathan, ceramics are considered as high-entropy materials if they consist of five binary ceramic phases [3]. Here we want to mention that it is probably not the high configurational entropy per se leading to substantially enhanced material properties like strength, toughness, thermal stability, and oxidation resistance. Only if the single-phase alloys (or the matrix of a more complex material) are composed of at least 5 principal elements (leading to $\Delta \mathrm{S}_{\text {conf }}>1.5 \cdot \mathrm{R}$ ) they outperform conventional alloys (which are typically based only on 1 , 2 , or 3 principal elements). Connected with this condition (at least 5 principal elements) is not only a high configurational entropy but also a severe lattice distortion, a sluggish diffusion, and a cocktail 
(a)

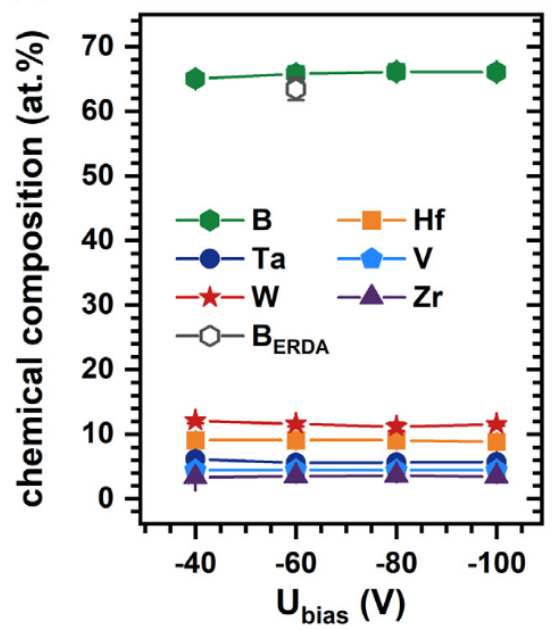

(b)

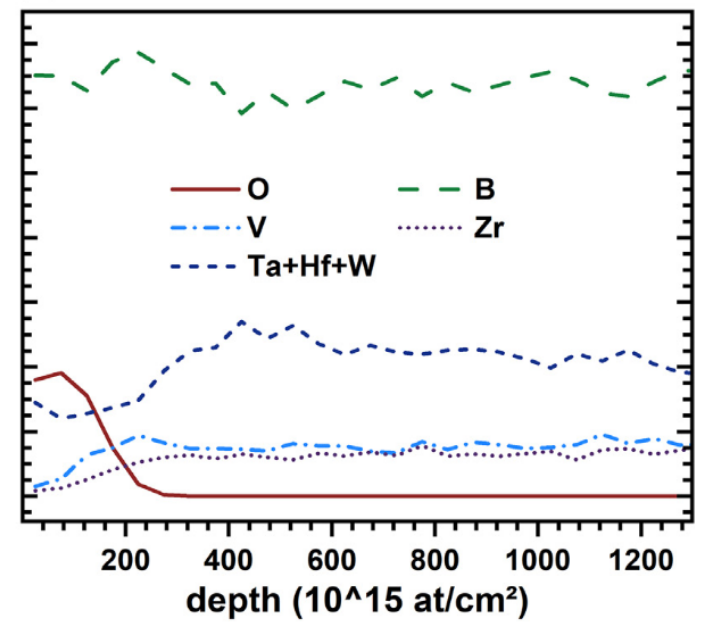

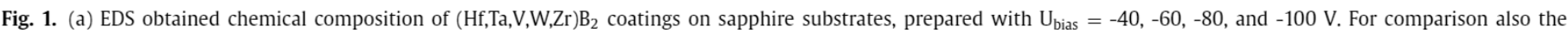
ERDA obtained $B$ content is added for the sample prepared with $U_{\text {bias }}=-60 \mathrm{~V}$. (b) ERDA depth profile for the sample prepared with $U_{\text {bias }}=-60 \mathrm{~V}$.
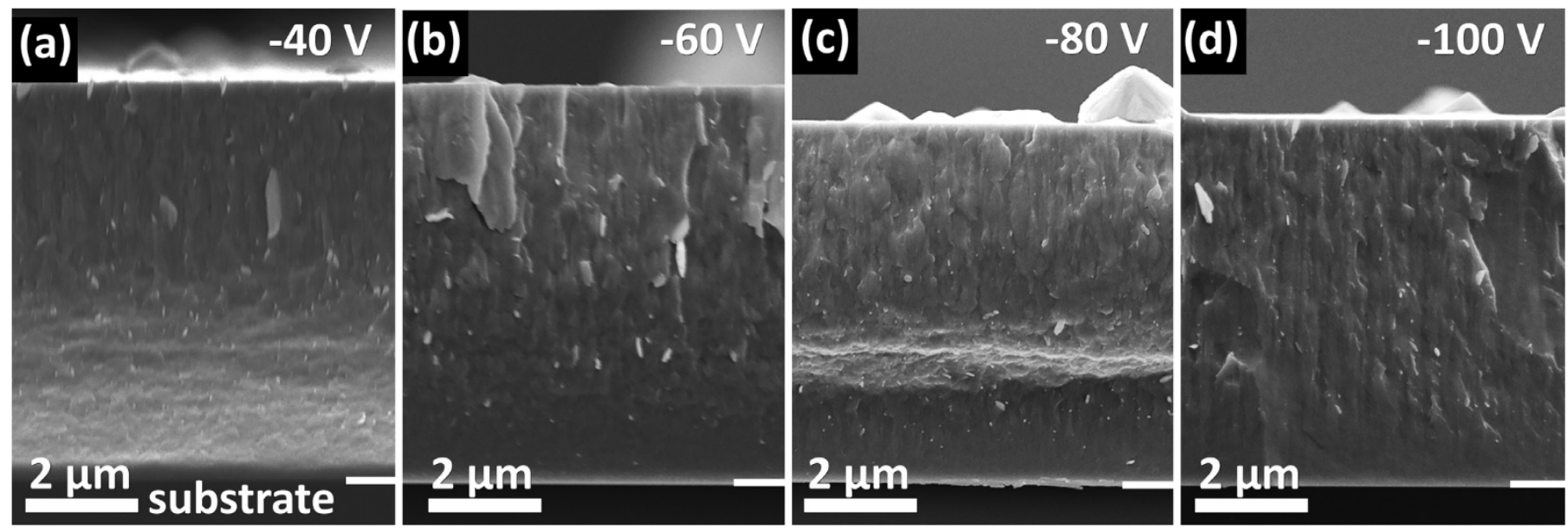

Fig. 2. SEM fracture cross-sections of $(\mathrm{Hf}, \mathrm{Ta}, \mathrm{V}, \mathrm{W}, \mathrm{Zr}) \mathrm{B}_{2}$ coatings deposited with $\mathrm{U}_{\text {bias }}=(\mathrm{a})-40 \mathrm{~V}$, (b) $-60 \mathrm{~V}$, (c) $-80 \mathrm{~V}$, and (d) $-100 \mathrm{~V}$ on sapphire substrates.

effect (cumulative properties and positive deviation from the arithmetic mean value, i.e., like a cocktail being more colourful and arched or more colourful and tastier than its components). More recently, we proposed to refer to such compounds as high-entropy metal-sublattice ceramics [4]. Based on the HEA concept, borides, carbides, and oxides in bulk form have been studied regarding their mechanical properties, thermal stability, and oxidation resistance. Also these often show significantly improved materials characteristics compared to their constituting binaries [5-11]. Later, such a high-entropy concept for ceramic materials was also applied to thin films. First investigations concentrated on (Al,Cr,Ta,Ti,Zr)N coatings, which exhibit minor dependence of their structural and mechanical properties on varying the deposition parameters such as reactive gas flow, substrate bias potential, and substrate temperature [12-14]. Additionally, this material system shows excellent thermal stability and diffusion barrier abilities for $\mathrm{Cu}$ [15]. Further studies on such thin films (actually composed of sublattice(s) with a high entropy) include investigations of refractory metal nitrides as well as oxide coatings with attractive mechanical properties and improved thermal stability [4],[16]. Recent investigations on diborides highlighted the potential in improving ceramiclike thin film materials when containing a high-entropy metalsublattice [17]. In analogy to the HEA concept, and based on our previous studies [4],[17], we suggest that the term "high-entropy sublattice (HES) concept" would be more adequate for multicomponent ceramic thin film materials, if the configuration entropy of at least one sublattice exceeds $1.5 \cdot R$.

Here, we study the phase formation, thermal stability and mechanical properties of single-phase solid solution ( $\mathrm{Hf}, \mathrm{Ta}, \mathrm{V}, \mathrm{W}, \mathrm{Zr}) \mathrm{B}_{2}$ developed by non-reactive magnetron sputtering of a powdermetallurgically produced compound target. The material system was chosen based on previous studies on binary and ternary diboride coatings within the system Hf-Ta-V-W-Zr [17-20] and after discussion with the target manufacturer. To avoid any confusion, we mention that we use the term binary diboride (carbide, nitride, or oxide) for compounds containing one other element aside from $\mathrm{B}(\mathrm{C}, \mathrm{N}$, or $\mathrm{O})$. Hence, to connect the term with the underlying binary system as well as binary phases, as done previously [44,45]. The corresponding terminology applies to ternary and higher order diborides (carbides, nitrides, or oxides). The developed highentropy metal-sublattice diboride (HESB) thin films show no significant dependence on the bias potential used during deposition, based on investigations by X-ray diffraction (XRD), scanning electron microscopy (SEM), and nanoindentation. Therefore, only the coating prepared with a bias potential of $-60 \mathrm{~V}$ was further investigated with respect to thermal stability, for which we used 


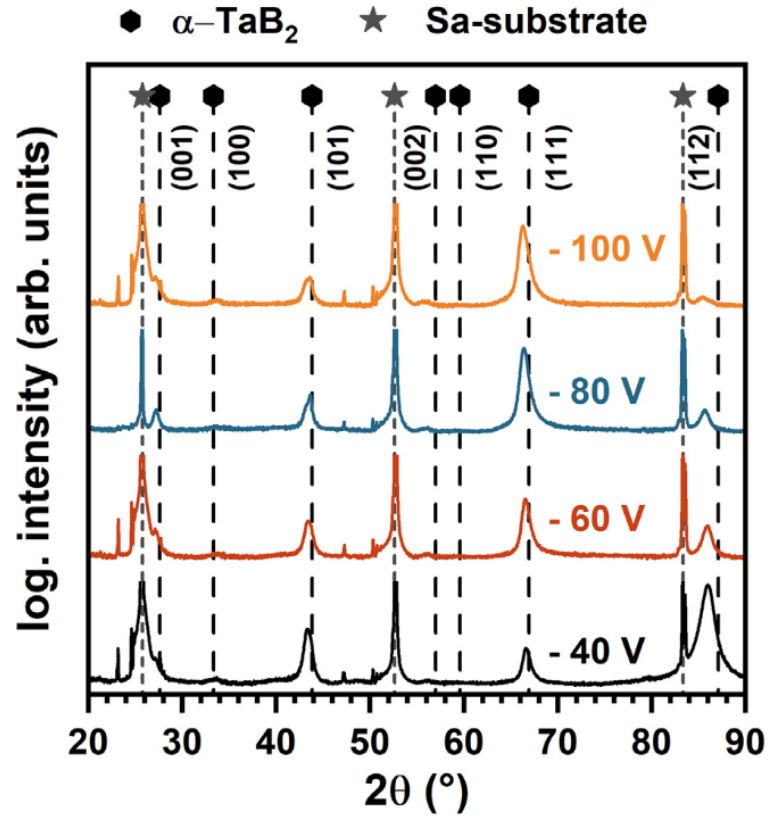

Fig. 3. XRD patterns of $(\mathrm{Hf}, \mathrm{Ta}, \mathrm{V}, \mathrm{W}, \mathrm{Zr}) \mathrm{B}_{2}$ coatings deposited on sapphire substrates with $\mathrm{U}_{\text {bias }}=-40,-60,-80$, and $-100 \mathrm{~V}$. The $\alpha$-structure is indicated by an $\alpha-\mathrm{TaB}_{2}$ (ICDD 00-038-1462) as this reference pattern yields the closest match to the solid solution $(\mathrm{Hf}, \mathrm{Ta}, \mathrm{V}, \mathrm{W}, \mathrm{Zr}) \mathrm{B}_{2}$, substrate peak positions are indicated by grey stars.

detailed XRD, nanoindentation (hardness $\mathrm{H}$ and indentation modulus E), elastic recoil detection analysis (ERDA), and atom probe tomography (APT).

\section{Experimental and methods}

The $(\mathrm{Hf}, \mathrm{Ta}, \mathrm{V}, \mathrm{W}, \mathrm{Zr}) \mathrm{B}_{2}$ thin films were deposited by unbalanced non-reactive magnetron sputtering with a modified Leybold Z400 deposition system using four different bias potentials $\left(\mathrm{U}_{\text {bias }}=-40\right.$,

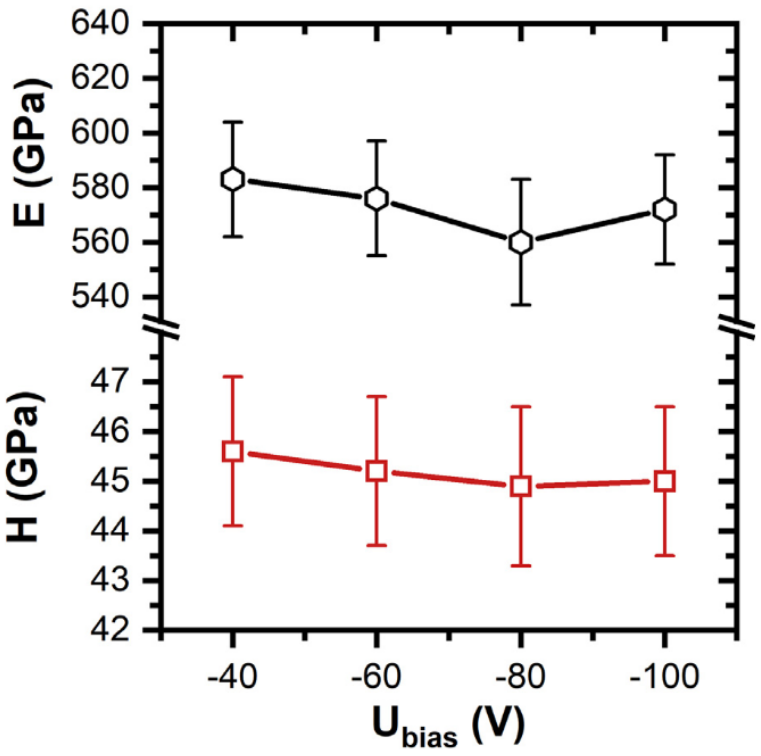

Fig. 4. Indentation modulus $\mathrm{E}$ and hardness $\mathrm{H}$ of single-phased solid solution $(\mathrm{Hf}, \mathrm{Ta}, \mathrm{V}, \mathrm{W}, \mathrm{Zr}) \mathrm{B}_{2}$ coatings on sapphire substrates deposited with $\mathrm{U}_{\text {bias }}=-40,-60$, -80 , and $-100 \mathrm{~V}$.

$-60,-80,-100 \mathrm{~V})$. We used one powder-metallurgically produced 3-inch composite diboride target consisting of $20 \mathrm{~mol}^{2} \mathrm{HfB}_{2}, \mathrm{TaB}_{2}$, $\mathrm{VB}_{2}, \mathrm{~W}_{2} \mathrm{~B}_{5}$, and $\mathrm{ZrB}_{2}$. The target-to-substrate distance (in a parallel concentrically arrangement) was $4 \mathrm{~cm}$. The substrates (polycrystalline $\mathrm{Al}_{2} \mathrm{O}_{3}$ and sapphire (1-102) platelets, and low alloyed steel foil) were ultrasonically cleaned in acetone and ethanol for 10 min prior to loading to the deposition chamber. After reaching a base pressure of $\leq 0.3 \mathrm{mPa}$ they were Ar-ion etched with -150 $\mathrm{V}$ pulsed DC (150 kHz, $2496 \mathrm{~ns})$ at an Ar gas pressure of $1.3 \mathrm{~Pa}$. During deposition, the substrate temperature $\left(T_{S}\right)$ was $450^{\circ} \mathrm{C}$, the Ar gas pressure was $0.35 \mathrm{~Pa}$ ( $\mathrm{Ar}$ gas flow rate of $30 \mathrm{sccm}$ ), the
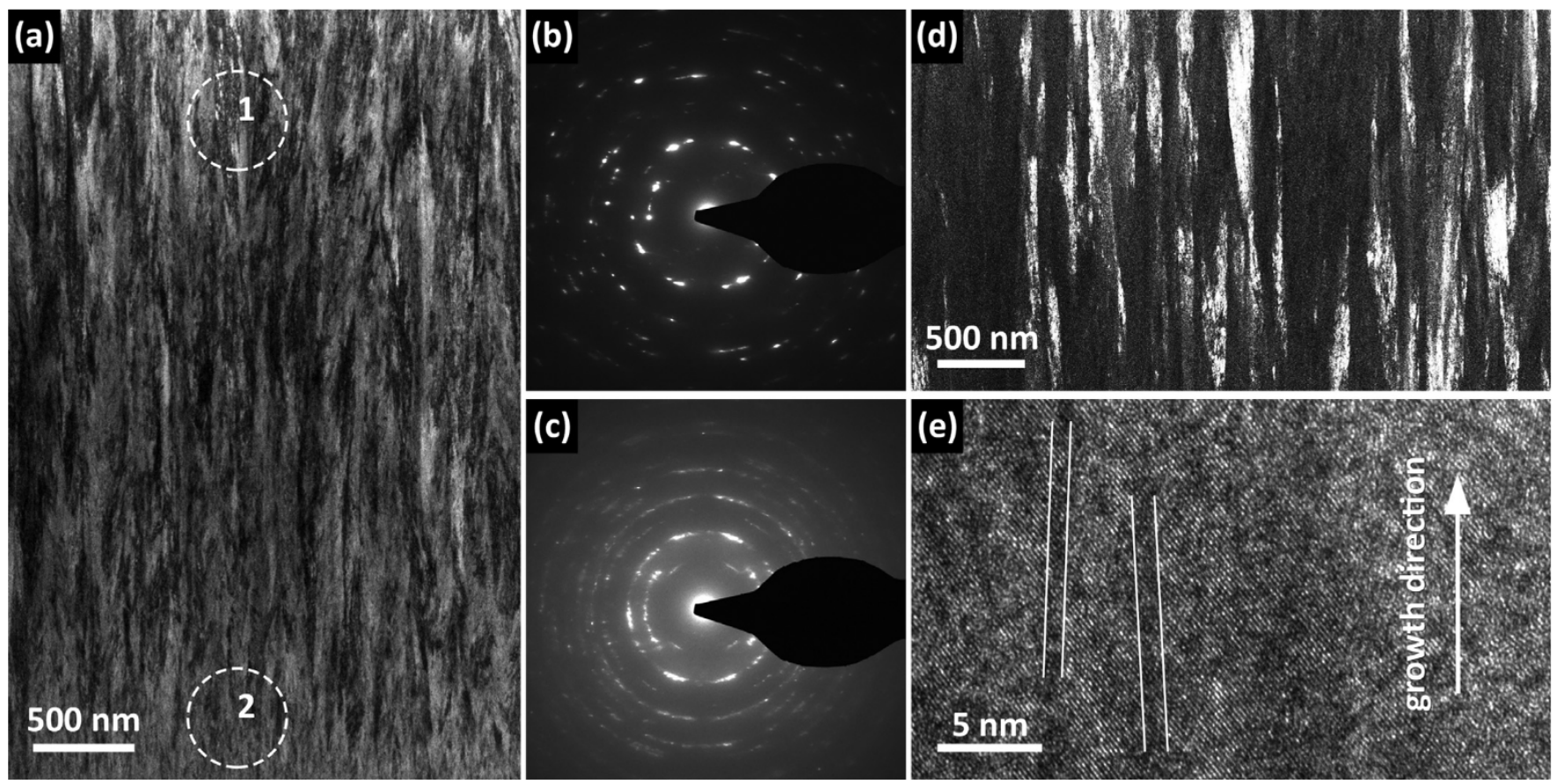

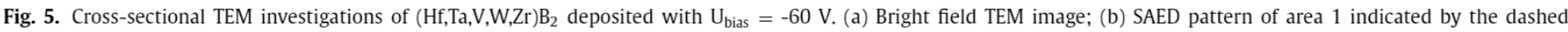

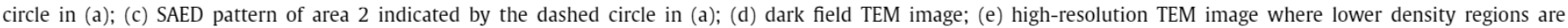
indicated with white lines. 
(a)

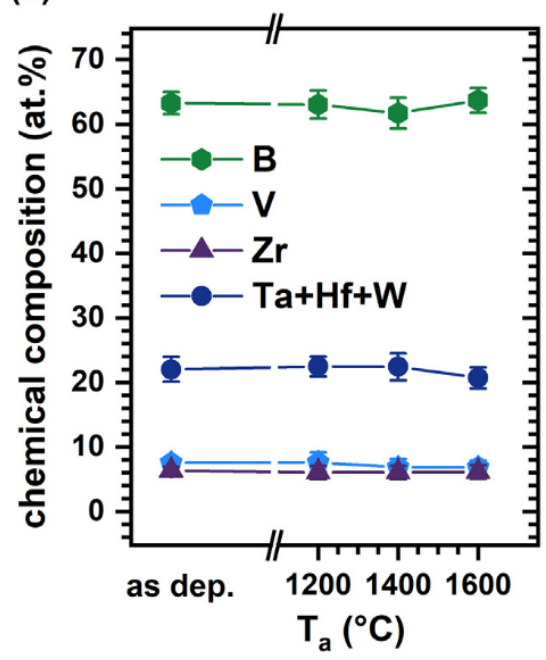

(b)

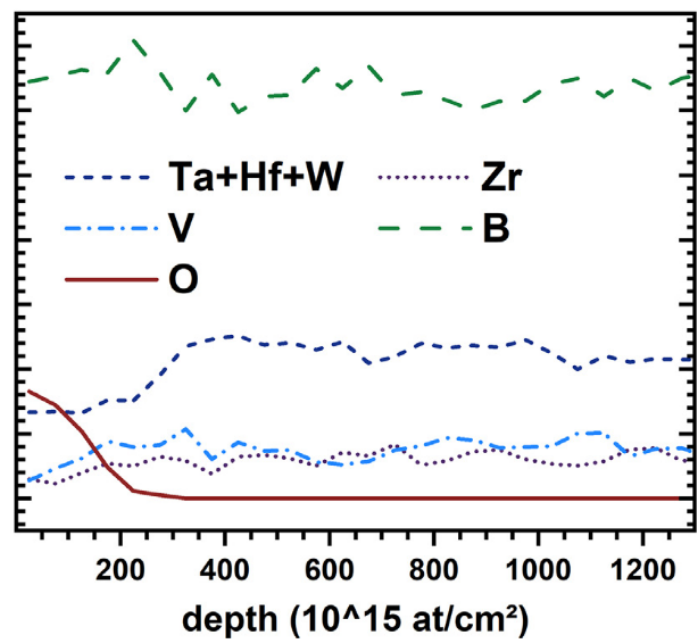

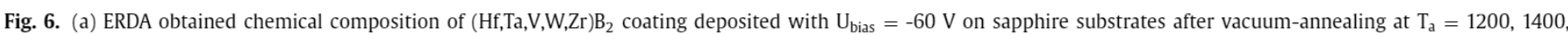
and $1600^{\circ} \mathrm{C}$. (b) ERDA obtained depth profile of the sample annealed at $1200^{\circ} \mathrm{C}$

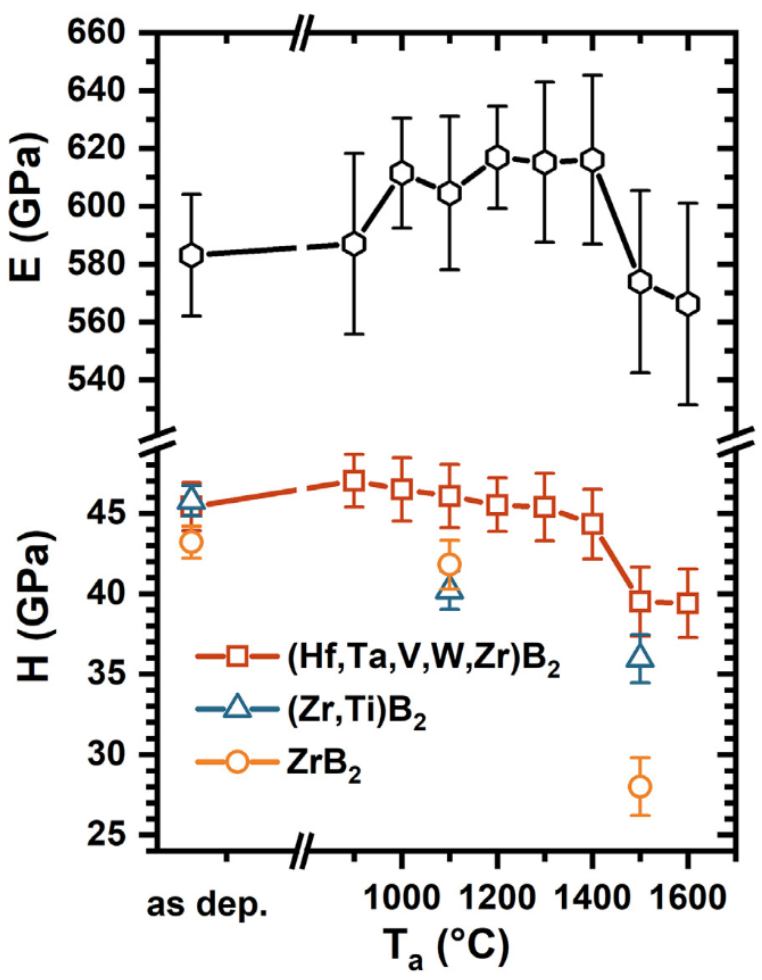

Fig. 7. Indentation modulus $\mathrm{E}$ and hardness $\mathrm{H}$ of $(\mathrm{Hf}, \mathrm{Ta}, \mathrm{V}, \mathrm{W}, \mathrm{Zr}) \mathrm{B}_{2}$ deposited with $\mathrm{U}_{\text {bias }}=-60 \mathrm{~V}$ on sapphire substrates after vacuum-annealing at $\mathrm{T}_{\mathrm{a}}=900,1000$, $1100,1200,1300,1400,1500$, and $1600^{\circ} \mathrm{C}$ for $10 \mathrm{~min}$. For comparison we added the data of $\mathrm{ZrB}_{2}$ and $(\mathrm{Zr}, \mathrm{Ti}) \mathrm{B}_{2}$ from Ref.[17].

DC sputter power density was $4.7 \mathrm{~W} / \mathrm{cm}^{2}$, and the substrate bias potentials were either $-40,-60,-80$, or $-100 \mathrm{~V}$. If we assume an average melting temperature $\mathrm{T}_{\mathrm{m}}$ of around $3240 \mathrm{~K}$ (from a linear interpolation of all the corresponding diborides), the $450^{\circ} \mathrm{C}(\sim 723$ $\mathrm{K})$ yields a homologues temperature $\left(\mathrm{T}_{\mathrm{s}} / \mathrm{T}_{\mathrm{m}}\right)$ of $\sim 0.22$ [21-25]. Fracture cross sections of our coatings are studied with a FEI Quanta 200 SEM - equipped with a field emission gun (FEG) and operated at an acceleration voltage of $10 \mathrm{kV}$ - for their growth morphology. Their chemical composition was obtained by top-view investiga- tions via energy dispersive X-ray spectroscopy (EDS) using a FEI Philips XL30 SEM equipped with an EDAX EDS detector. The boron content was additionally evaluated for the sample prepared with -60 V bias by time-of-flight elastic recoil detection analysis (TOFERDA) with a recoil detection angle of $45^{\circ}$ using a $36 \mathrm{MeV} \mathrm{I}^{8+}$ ion beam. This coating was studied in its as-deposited state as well as after the 10 -min-vacuum-annealing at 1200,1400 , and $1600^{\circ} \mathrm{C}$ (next but one paragraph) by TOF-ERDA. Details of the method, employed set-up, and accelerator are described elsewhere [26],[27]. Transmission electron microscopy (TEM) images as well as selected area electron diffraction (SAED) patterns were obtained using a TECNAI F20 FEG-TEM operated at $200 \mathrm{keV}$.

Coatings on sapphire substrates as well as coating material removed from low alloy steel foil (by chemically dissolving the foil with a diluted $\mathrm{HNO}_{3}$ ) are characterized by XRD using a PANalytical XPert Pro MPD ( $\theta-\theta$ diffractometer) equipped with a $\mathrm{Cu}-$ $\mathrm{K}_{\alpha}(\lambda=1.54 \AA)$ radiation source. Mechanical properties, indentation modulus $\mathrm{E}$ and hardness $\mathrm{H}$, of the coatings on sapphire substrates (in their as-deposited state and after vacuum annealing, next paragraph) were obtained by evaluating nanoindentation load-displacement curves according to the method from Oliver and Pharr [28]. For this we used a UMIS II nanoindentation system and recorded 45 load-displacement curves for each measurement point, starting at a load of $32 \mathrm{mN}$ and decreasing the load in 0.5 $\mathrm{mN}$ steps down to $10 \mathrm{mN}$. The maximum indentation depth was always below $210 \mathrm{~nm}$ and hence significantly below 10\% of the coating thickness, which was $\sim 6.5 \mu \mathrm{m}$.

Powder samples as well as coatings on sapphire substrates (prepared with $-60 \mathrm{~V}$ bias potential) were vacuum annealed in a Centorr LF22-2000 vacuum furnace (base pressure $0.8 \mathrm{mPa}$ ) at $\mathrm{T}_{\mathrm{a}}$ (varied between 900 and $1600^{\circ} \mathrm{C}$ in $100^{\circ} \mathrm{C}$ steps) for $10 \mathrm{~min}$. The heating rate was $20 \mathrm{~K} / \mathrm{min}$ and the cooling rate (passively, by turningoff the heater) down to $200^{\circ} \mathrm{C}$ was $>50 \mathrm{~K} / \mathrm{min}$. After these heat treatments the samples were again investigated by XRD, nanoindentation, and EDS.

Furthermore, the coatings prepared with $-60 \mathrm{~V}$ bias potential are studied in detail for the element distribution in their asdeposited state and after vacuum annealing at 1200, 1400, and $1600^{\circ} \mathrm{C}$ with APT. The three-dimensional spatially-resolved chemical composition at the nanometer scale of $(\mathrm{Hf}, \mathrm{Ta}, \mathrm{V}, \mathrm{W}, \mathrm{Zr}) \mathrm{B}_{2}$ was investigated using a CAMECA local electrode atom probe $4000 \mathrm{X}$ HR. Laser-assisted field evaporation was employed with $50 \mathrm{pJ}$ laser 
(a)

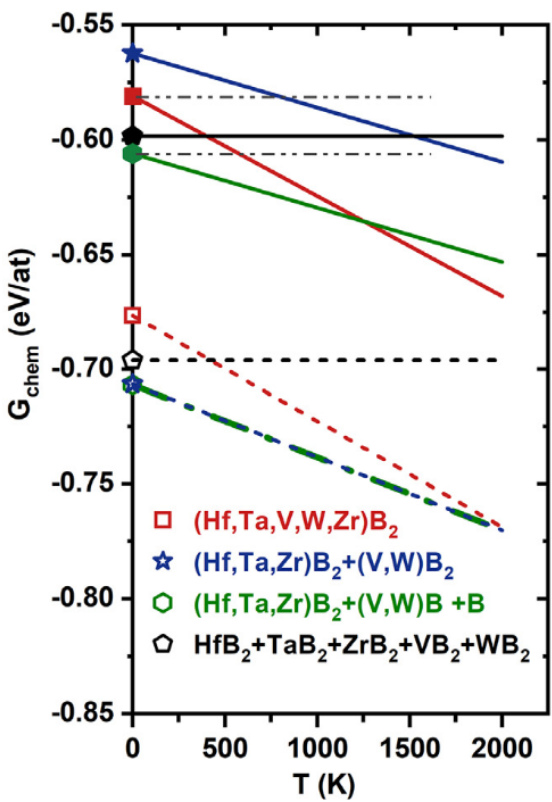

(b)

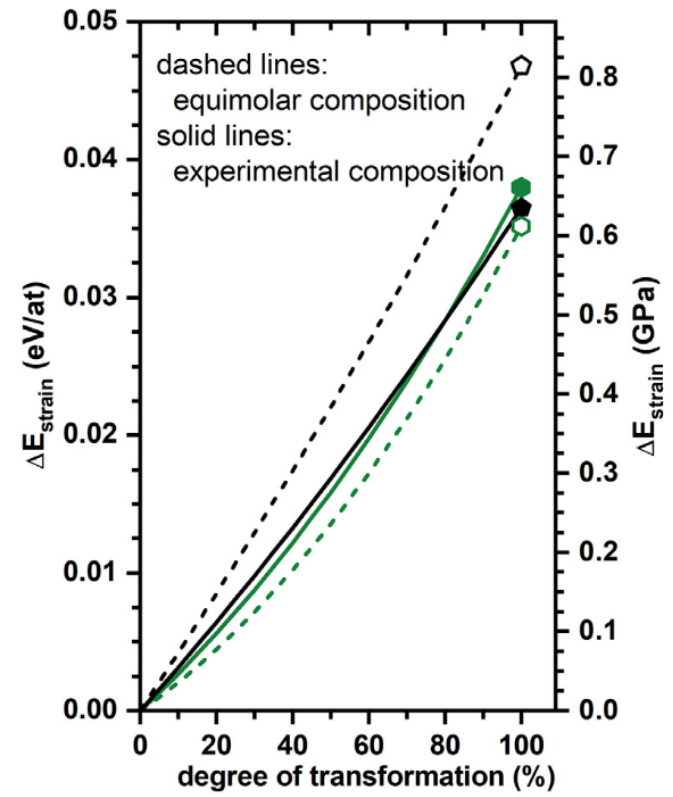

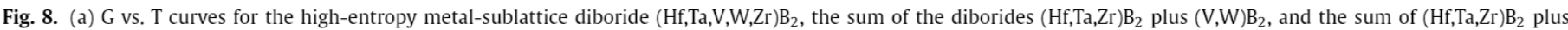

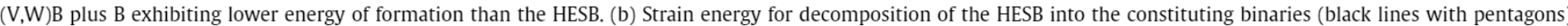

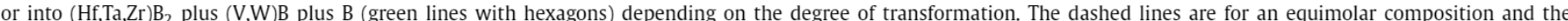
solid lines are for a chemical composition close to the experimentally obtained values (by ERDA and EDS).

pulse energy, $200 \mathrm{kHz}$ laser pulse frequency, and $60 \mathrm{~K}$ base temperature. The average detection rate was set to $1 \%$ and at least 15 million ions were obtained for each measurement. Needle-shape specimens were prepared by focused ion beam (FIB) techniques using a FEI Helios Nanolab 660 dual-beam microscope and following a standard approach [29]. These specimens were extracted parallel to the growth direction from powdered free-standing coating material. The region of interest was protected with a 350-nm-thin Pt layer against $\mathrm{Ga}$ implantation and this protection layer was removed during the final milling of the specimens.

The energy of formation of $(\mathrm{Hf}, \mathrm{Ta}, \mathrm{V}, \mathrm{W}, \mathrm{Zr}) \mathrm{B}_{2},(\mathrm{Hf}, \mathrm{Ta}, \mathrm{Zr}) \mathrm{B}_{2}$ and $(\mathrm{V}, \mathrm{W}) \mathrm{B}_{2}$ in their $\mathrm{AlB}_{2}$ prototype structure (space group 191 (P6/mmm), shortly $\alpha$-type structure) is obtained by density functional theory (DFT) calculations employing the Vienna Ab Initio Simulation Package (VASP) [30]. Structure optimization was obtained by applying the projector augmented wave method within the general gradient approximation (GGA) parameterized by Perdew, Burke, and Ernzerhof [31], of solid solutions treated with the special quasirandom structure approach (applying the ATAT simulation package [32]). Energy cutoff and k-point mesh were chosen carefully, to ensure energy convergence of a few meV/at, for all calculations. To reach an equimolar composition of the ( $\mathrm{Hf}, \mathrm{Ta}, \mathrm{V}, \mathrm{W}, \mathrm{Zr}$ ) $\mathrm{B}_{2}$, for all diboride compositions a $5 \times 5 \times 2$ supercell was created (containing 150 atoms). For the calculations regarding $(\mathrm{V}, \mathrm{W}) \mathrm{B}$ (space group $63(\mathrm{cmcm}))$, a $2 \times 2 \times 2$ supercell containing 64 atoms was chosen. The experimental composition for all calculations was taken from the EDS measurements. Furthermore, the elastic constants were calculated by applying the stressstrain-method [33]. These were used to determine the polycrystalline Youngś modulus Y and the Poisson ratio [34-36].

To evaluate the strain energy density resulting from a phase transition of the solid solution $(\mathrm{Hf}, \mathrm{Ta}, \mathrm{V}, \mathrm{W}, \mathrm{Zr}) \mathrm{B}_{2}$ phase into different daughter phases we apply continuum mechanics mean field theories. A phase transition generally leads to a change of specific volume, inducing eigenstrains which have to be accommodated by elastic deformation of the matrix and the newly formed phases.
- (Hf,Ta,Zr)B $B_{2} \quad \star \quad(\mathrm{V}, \mathrm{W}) \mathrm{B} \quad \diamond \quad(\mathrm{Hf}, \mathrm{Ta}, \mathrm{V}, \mathrm{W}, \mathrm{Zr}) \mathrm{B}_{2}$

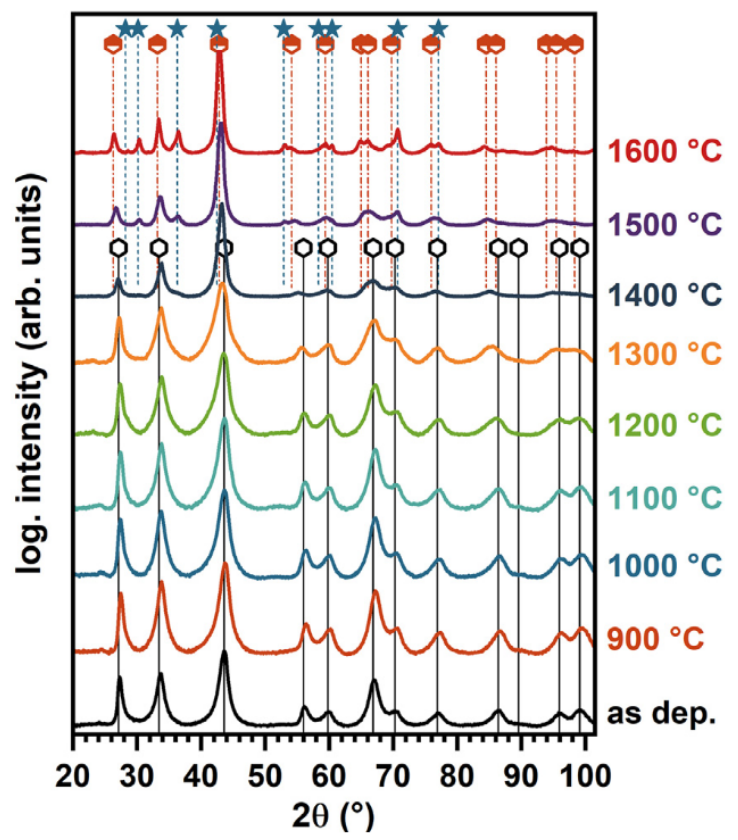

Fig. 9. XRD patterns of vacuum-annealed (at different temperatures, indicated next to the individual patterns) powdered free-standing coating material. The empty black hexagons indicate the XRD peak positions for an $\mathrm{AlB}_{2}$-structure with lattice parameters of $\mathrm{a}=3.09 \AA$ and $\mathrm{c}=3.28 \AA$. The half-filled red hexagons indicate the XRD peak positions for an $\mathrm{AlB}_{2}$-structure with lattice parameters of $\mathrm{a}=3.11 \AA$ and $c=3.39 \AA$. Based on APT investigations (presented later) this is indicated with (Ta, $\mathrm{Zr}, \mathrm{Hf}) \mathrm{B}_{2}$. The blue stars mark the XRD peak positions for an orthorhombic structure (CrB-structure space group $63(\mathrm{cmcm}))$ with lattice parameters of a $=3.16 \AA$, $\mathrm{b}=8.41 \AA$, and $\mathrm{c}=3.06 \AA$, which is indicated with $(\mathrm{V}, \mathrm{W}) \mathrm{B}$, also based on the APT investigations (presented later). 

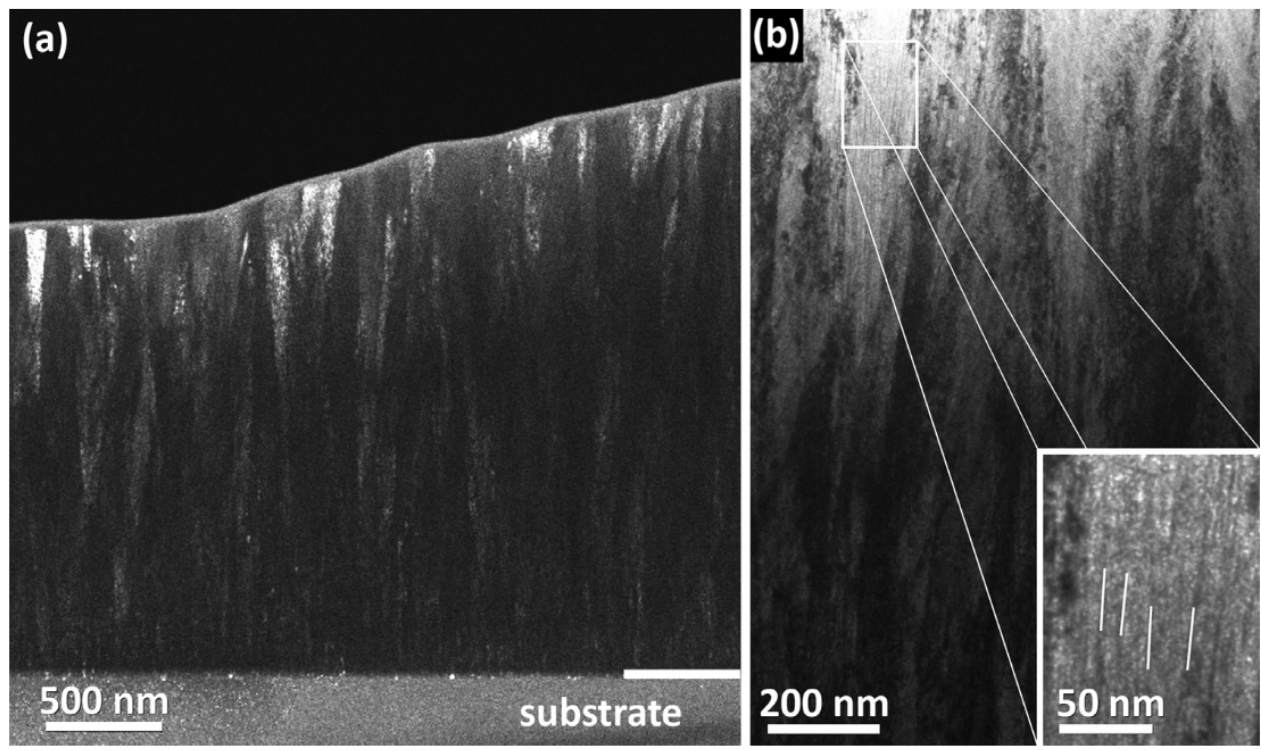

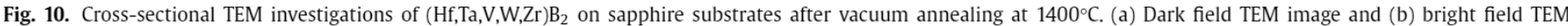
image with a higher resolution inset illustrating the more distinct (as compared to the as-deposited state) nanocolumnar structure elongated in growth direction.

The specific volumes of the phases $\mathrm{V}^{\mathrm{P}}$ and the matrix $\mathrm{V}^{\mathrm{M}}$ were taken from $a b$ initio calculations. The volume change $\delta^{\mathrm{P}}$ is then calculated by

$\delta^{\mathrm{P}}=\frac{\mathrm{V}^{\mathrm{P}}-\mathrm{V}^{\mathrm{M}}}{\mathrm{V}^{\mathrm{M}}}$

For all constituents, isotropic material behaviour is considered with polycrystalline elastic properties obtained by applying the Voigt-Reuss scheme to the ab initio calculated stiffness tensor. The precipitates are assumed to be of spherical shape with purely volumetric transformation strains, hence, the eigenstrain tensor is calculated by

$\varepsilon_{\mathrm{ij}}^{* \mathrm{p}}=\frac{\delta^{\mathrm{P}}}{3} \cdot \delta_{\mathrm{ij}}$

with $\delta_{\mathrm{ij}}$ being the unity tensor. To account for the different eigenstrains and their interactions in a multiphase system, we used a Mori-Tanaka-based Transformation Field Analysis [37],[38]. Boundary conditions are set to correspond with vanishing macroscopic strains, whereas the macroscopic stresses are nonzero. We assume simultaneous formation of the daughter phases and study the strain energy density as a function of the degree of transformation.

\section{Results and discussion}

The EDS obtained chemical compositions of the different ( $\mathrm{Hf}, \mathrm{Ta}, \mathrm{V}, \mathrm{W}, \mathrm{Zr}$ ) diboride coatings suggest an almost $\mathrm{MeB}_{2}$ stoichiometry with boron contents between 65 and 66 at\%, independent of the bias potential used, Fig. 1a. The composition depth profile obtained by ERDA for the sample prepared with $U_{\text {bias }}=-60$ $\mathrm{V}$ reveals $63 \pm 1.7$ at\% B, Fig. 1b, in excellent agreement with EDS data. The contents of the metallic elements are $\sim 12$ at $\% \mathrm{~W}, \sim 9$ at $\%$ Hf, $\sim 6$ at\% Ta, $\sim 5$ at\% V, and $\sim 4$ at\% Zr. Due to the energetically similar shell transitions of $\mathrm{W}$ and $\mathrm{Zr}$, they are hard to separate by EDS, but ERDA indicates a $\mathrm{Zr}$ content of 6.6 at\% and a $\mathrm{V}$ content of 7.8 at\%. However, by ERDA the elements Hf, Ta, and W (neighbours in the periodic table) are difficult to separate. Nevertheless, except for a slight O-enriched surface, the depth-profile from the ERDA measurement indicates a homogenous element distribution over the whole sample volume investigated.
The individual samples show chemical composition variations within the error of EDS measurements ( \pm 1 at $\%$ ), therefore we conclude that their average chemistry is independent of the bias potential used during this investigation. Based on EDS, and normalising to stoichiometric $\mathrm{MeB}_{2}$, the nomenclature of the coatings corresponds to $\left(\mathrm{Hf}_{0.25} \mathrm{Ta}_{0.17} \mathrm{~V}_{0.14} \mathrm{~W}_{0.33} \mathrm{Zr}_{0.11}\right) \mathrm{B}_{2}$. This causes a configurational entropy $\Delta \mathrm{S}_{\text {conf }}$ of $1.53 \cdot \mathrm{R}$ per formula unit, and classifies the synthesised diborides as high-entropy metal-sublattice diborides (HESB) according to the above-mentioned definition $\left(\Delta \mathrm{S}_{\text {conf }} \geq\right.$ $1.5 \cdot \mathrm{R}$ ). Using the $\mathrm{Zr}$ and $\mathrm{V}$ contents from ERDA (which are higher than those obtained from EDS) the configurational entropy is even higher, as the metal-sublattice is closer to an equimolar composition.

All coatings exhibit a fine-fibrous growth morphology (independent of the bias potential applied, Fig. 2a-d) with a nearly featureless appearance for the initial growth region close to the sapphire substrate. With increasing bias potential from -40 to $-100 \mathrm{~V}$ the growth rate only slightly decreases from $\sim 110$ to $\sim 80 \mathrm{~nm} / \mathrm{min}$.

XRD investigations of all coatings clearly demonstrate a singlephase solid solution diboride with $\alpha$-structure, see Fig. 3 exemplarily showing XRD patterns of coatings grown on sapphire. For $\mathrm{U}_{\text {bias }}=-40 \mathrm{~V}$ these show a preferred (112)-oriented growth that changes towards a (111)-oriented growth with increasing $U_{\text {bias }}$ to -100 V, Fig. 3.

The XRD peak positions of this HESB suggest lattice parameters of $\mathrm{a}=3.09 \AA$ and $\mathrm{c}=3.28 \AA$. These are in very good agreement with the linearly interpolated lattice parameters between $\mathrm{HfB}_{2}$, $\mathrm{TaB}_{2}, \mathrm{VB}_{2}, \mathrm{WB}_{2}$, and $\mathrm{ZrB}_{2}$ (from ICDD reference data) - using their above-mentioned chemical composition - which are $a=3.08 \AA$ and $\mathrm{c}=3.24 \AA$.

Indentation modulus $\mathrm{E}$ and hardness $\mathrm{H}$ of the samples are $\sim 580$ GPa and $45 \mathrm{GPa}$, respectively, independent of the substrate bias potential applied, Fig. 4. The individual values are within the error of measurement of about $\pm 20 \mathrm{GPa}$ for $\mathrm{E}$ and $\pm 1.5 \mathrm{GPa}$ for $\mathrm{H}$. This is also because the growth morphology is nearly independent of the bias potential used, and already for a relatively low $\mathrm{U}_{\text {bias }}$ of $-40 \mathrm{~V}$, a rather dense fine-fibrous growth morphology is obtained, Fig. 2. The relatively constant mechanical properties for the different bias potentials suggest that these are also independent of the preferred growth orientation, which does change with the bias potential (see Fig. 3). 
(a)

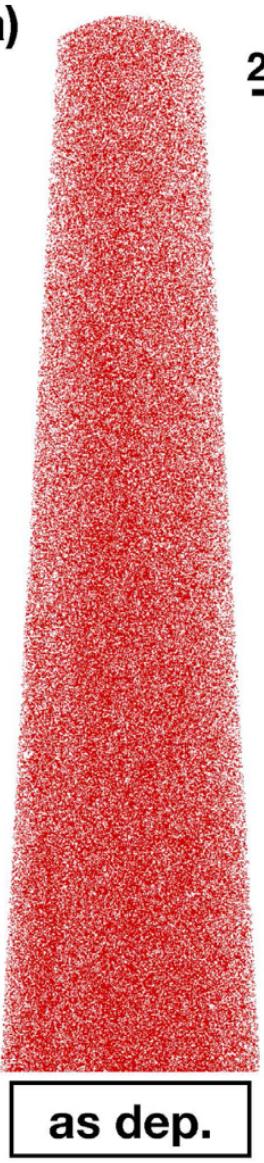

$\underline{25 \mathrm{~nm}}$

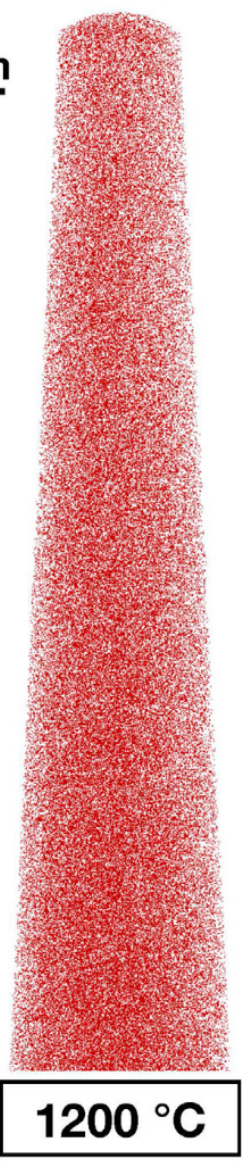

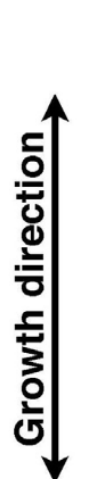

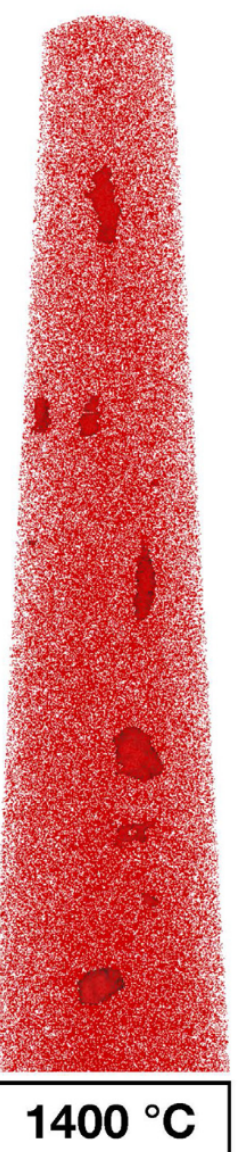

(b)

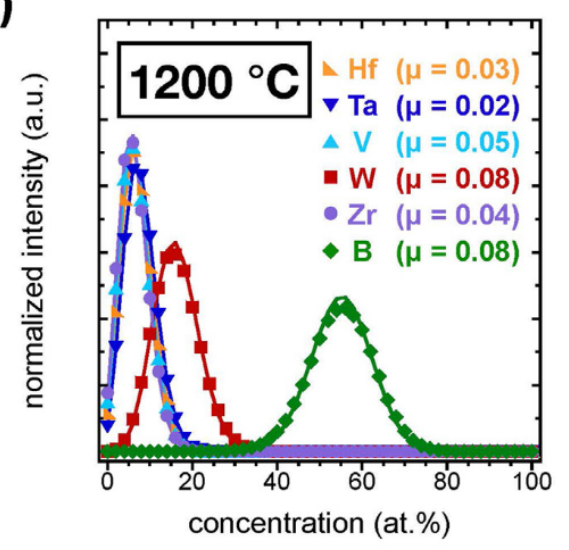

(c)

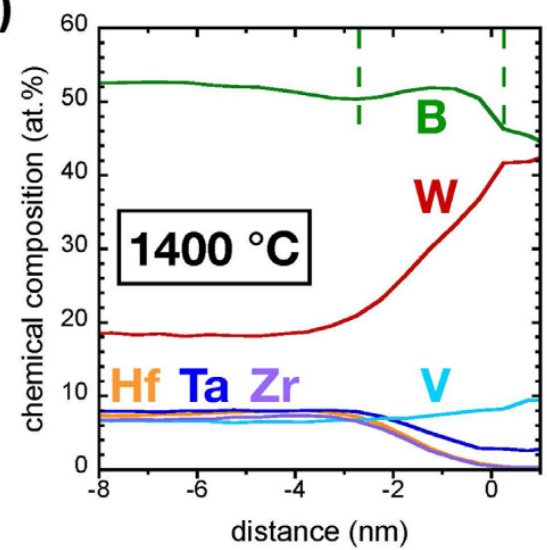

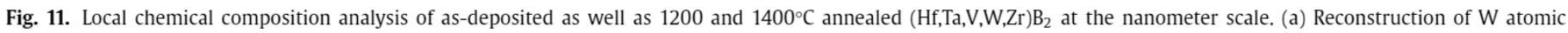

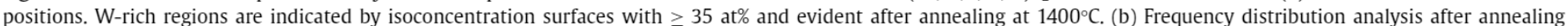

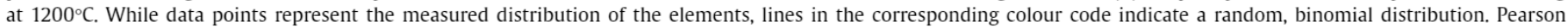

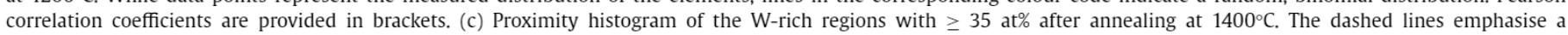
confined B enrichment at the interface region.

Detailed cross-sectional TEM studies of $(\mathrm{Hf}, \mathrm{Ta}, \mathrm{V}, \mathrm{W}, \mathrm{Zr}) \mathrm{B}_{2}$ prepared with $\mathrm{U}_{\text {bias }}=-60 \mathrm{~V}$ clearly confirm the dense fine-fibrous growth morphology, Fig. 5. At the interface to the substrate, their grain size is small, typical for random nucleation, followed by a competitive growth region. But even near to the coating surface, the column diameters are still rather small with about $80-100$ $\mathrm{nm}$, see Fig. 5a. The corresponding SAED investigations show distinct diffraction spots, Fig. 5b, highlighting the oriented columns with a large aspect ratio. The aperture size is indicated with a dashed circle in Fig. 5a, which is easily exceeded by a column length. Contrary, close to the substrate-coating interface the aperture size covers several column lengths and thus the corresponding SAED pattern is more ring-like rather than having distinct diffraction spots, Fig. 5c. The large aspect ratio of the columns close to the coating's surface is easily seen in the higher resolution dark field TEM image, Fig. 5d, suggesting for $\sim 1 \mu \mathrm{m}$ long and $50 \mathrm{~nm}$ wide columns. The contrast modulations during high-resolution TEM investigations (indicated by white lines in Fig. 5e) point towards a periodic chemical and/or strain variation along the relatively dense columns.

After vacuum-annealing at $T_{a}=1200,1400$, and $1600^{\circ} \mathrm{C}$, the investigated coating still shows the same average chemical composition as in their as-deposited state, see the ERDA results summarised in Fig. 6a. Even the boron content stays at 62 at\%, contrary to previous studies on high-entropy metal-sublattice diborides or Ti-B-N, where a significant B-loss upon vacuumannealing was observed on the account of volatile $\mathrm{H}_{3} \mathrm{BO}_{3}$ forma- tion [17,39]. Also, the ERDA depth profile of the coating annealed at $1200^{\circ} \mathrm{C}$ suggests only for a small surface-near region enriched in oxygen. The very similar 0 -depth profile to the as-deposited state indicates that there is no significant oxygen uptake during vacuum annealing.

Nanoindentation measurements of these coatings $\left(U_{\text {bias }}=-60\right.$ $\mathrm{V}$, sapphire substrate) after vacuum-annealing also suggest excellent thermal stability, at least up to $1400^{\circ} \mathrm{C}$. Their indentation modulus slightly increases from $580 \pm 20 \mathrm{GPa}$ to $610 \pm 30 \mathrm{GPa}$ upon annealing at $\mathrm{T}_{\mathrm{a}}$ up to $1400^{\circ} \mathrm{C}$, respectively, Fig. 7. If no phase transformation takes place, this indicates that the vacancy content decreases and/or the cohesive strength of grain or column boundary regions increases [39]. Both would be caused by the annealing treatment as thin films prepared by magnetron sputtering (at low homologues temperatures, as in the present case) typically exhibit an extensive vacancy content and underdense boundary regions [40]. Increasing $\mathrm{T}_{\mathrm{a}}$ further to 1500 and $1600^{\circ} \mathrm{C}$ leads to a noticeable reduction in $\mathrm{E}$ to $\sim 570 \mathrm{GPa}$.

The hardness of the $(\mathrm{Hf}, \mathrm{Ta}, \mathrm{V}, \mathrm{W}, \mathrm{Zr}) \mathrm{B}_{2}$ coating initially increases upon vacuum annealing, from $45.4 \pm 1.5$ to $47.0 \pm 1.6$ GPa with $\mathrm{T}_{\mathrm{a}}=$ $900{ }^{\circ} \mathrm{C}$. Raising $\mathrm{T}_{\mathrm{a}}$ to $1400^{\circ} \mathrm{C}$ causes a small but continuous decrease to $44.3 \pm 2.1 \mathrm{GPa}$. Similar to the behaviour of the indentation modulus, also the hardness shows a more distinct reduction upon further increasing $\mathrm{T}_{\mathrm{a}}$ to 1500 and $1600^{\circ} \mathrm{C}$. After which the hardness was "only" about 39.5 GPa, see Fig. 7.

These results indicate that a relatively small grain size and a high defect density (point defects due to the high-entropy metal- 

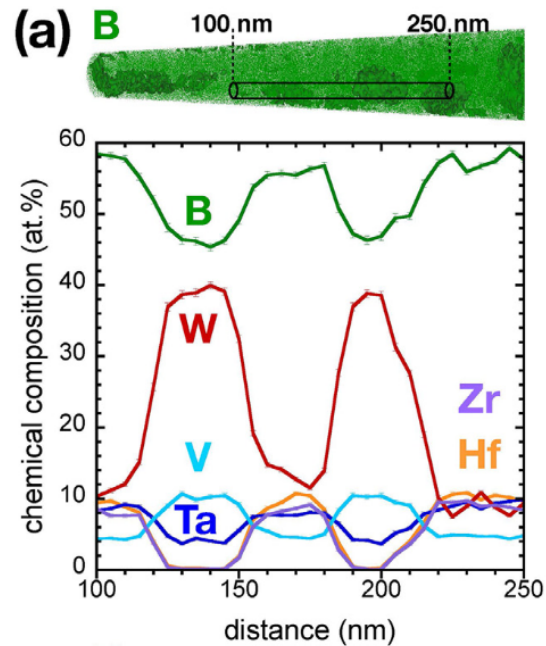

(d)
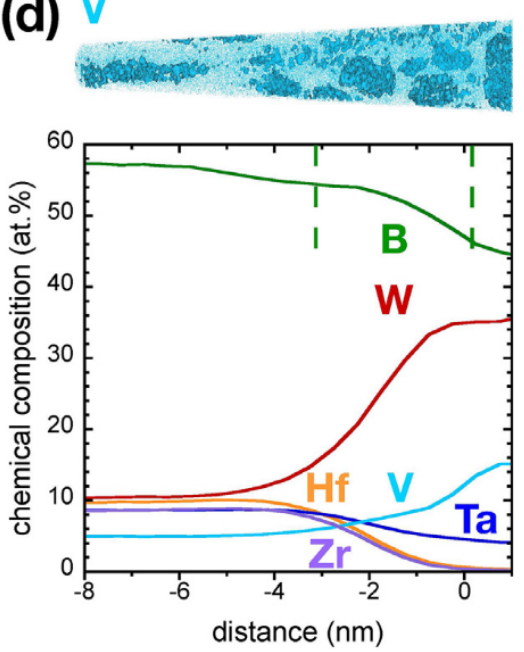

(b)
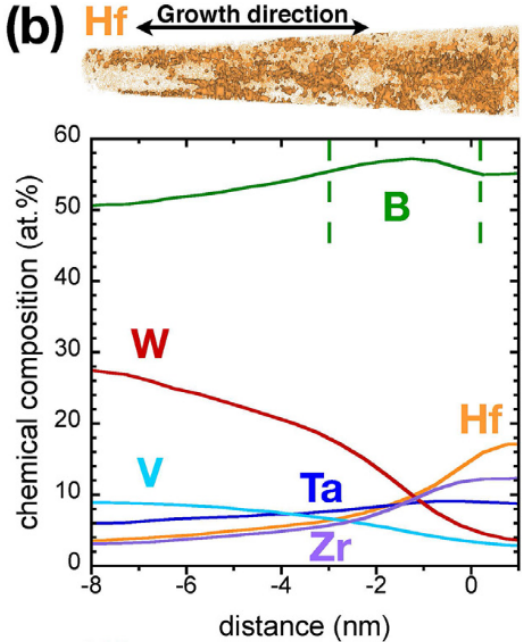

(e) $\mathrm{W}$
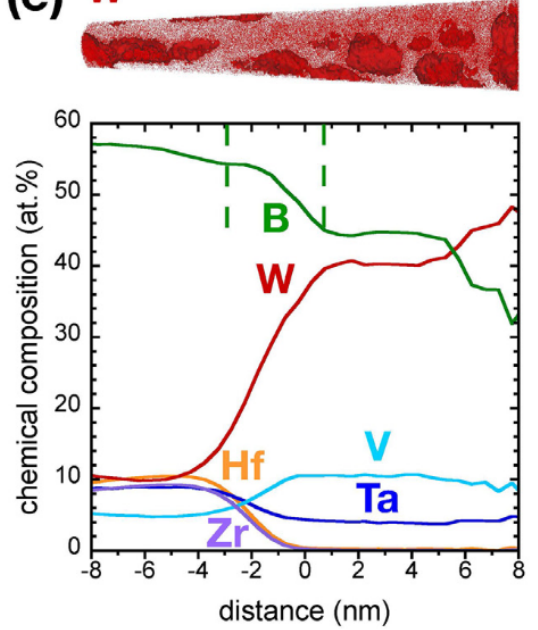

(c) $\mathrm{Ta}$ Fintate

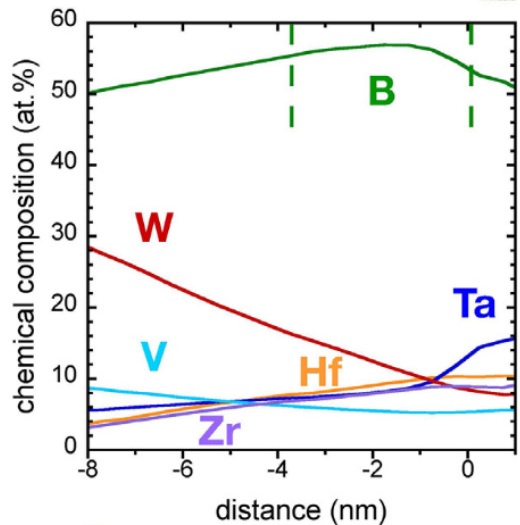

(f)
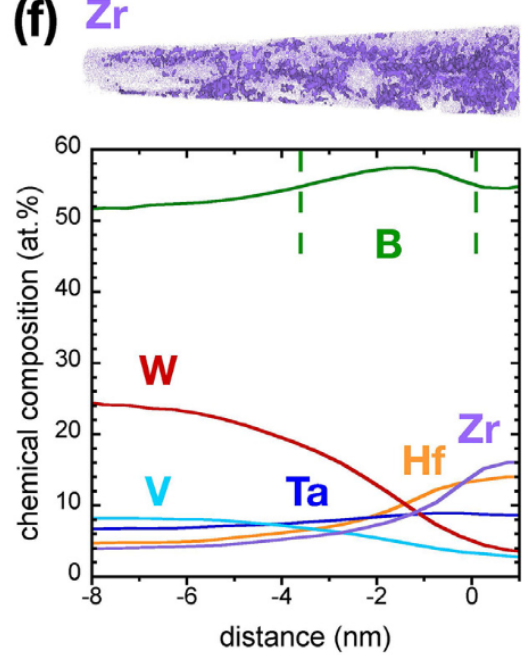

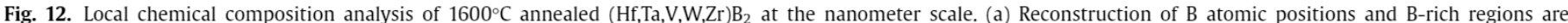

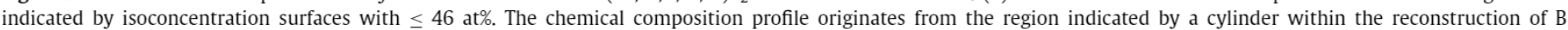

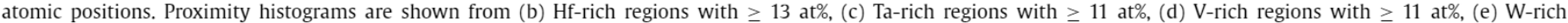

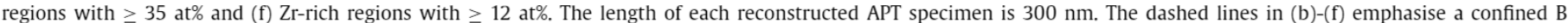
enrichment in the interface region.

sublattice, see next but one paragraph, and dislocations) is maintained leading to the preserved superhardness ( $\mathrm{H} \geq 40 \mathrm{GPa}$ ) up to $\mathrm{T}_{\mathrm{a}}=1400^{\circ} \mathrm{C}$. Thermally-induced recovery effects may essentially influence the vacancy content (to reach thermal equilibrium) and underdense boundary regions upon which the indentation modulus and hardness even increase up to $T_{a}=1400^{\circ} \mathrm{C}$. The more distinct decrease in $\mathrm{E}$ and $\mathrm{H}$ upon annealing at $\mathrm{T}_{\mathrm{a}}=1500$ and $1600^{\circ} \mathrm{C}$ is due to the decomposition of the high-entropy metalsublattice diboride, (Hf,Ta,V,W,Zr) $\mathrm{B}_{2}$, towards a $(\mathrm{Hf}, \mathrm{Ta}, \mathrm{Zr}) \mathrm{B}_{2}$ diboride and $(\mathrm{V}, \mathrm{W}) \mathrm{B}$ monoboride (the corresponding XRD studies are presented later). The binary $\mathrm{ZrB}_{2}$ or ternary $(\mathrm{Zr}, \mathrm{Ti}) \mathrm{B}_{2}$ (prepared with the same deposition equipment) show a significantly lower thermal stability, with a more pronounced impact of the annealing temperature especially on the hardness [17], see Fig. 7.

For an equimolar composition, the solid solution HESB phase has a less negative energy of formation $\left(E_{f}\right)$ - see Fig. 8a $(y-$ axis value for $0 \mathrm{~K}$, obtained by ab initio calculations) - than the corresponding binaries. This is also valid for the other equimolar cases considered here $\left[(\mathrm{Hf}, \mathrm{Ta}, \mathrm{Zr}) \mathrm{B}_{2}+(\mathrm{V}, \mathrm{W}) \mathrm{B}_{2}\right.$ and $\left.(\mathrm{Hf}, \mathrm{Ta}, \mathrm{Zr}) \mathrm{B}_{2}+(\mathrm{V}, \mathrm{W}) \mathrm{B}+\mathrm{B}\right]$. Hence, the formation of a single-phase HESB is least preferred. Contrary, for metal contents close to the experimentally obtained chemical composition, the HESB is already preferred at $0 \mathrm{~K}$ over the sum of $(\mathrm{Hf}, \mathrm{Ta}, \mathrm{Zr}) \mathrm{B}_{2}+(\mathrm{V}, \mathrm{W}) \mathrm{B}_{2}$ diboride formation, but again loses against the respective binaries and especially the formation of $(\mathrm{Hf}, \mathrm{Ta} . \mathrm{Zr}) \mathrm{B}_{2}+(\mathrm{V}, \mathrm{W}) \mathrm{B}+\mathrm{B}$. Simply using the configurational entropy (with $S_{\text {conf }}=-R \sum_{i=1}^{5} x_{i} \ln x_{i}$ and $x_{i}$ being the molar fraction of the constituting binary diborides) and the energy of formation $\mathrm{E}_{\mathrm{f}}$ of the solid solutions for the mixing enthalpy $\left(\mathrm{H}_{\text {mix }}\right)$ we obtained the Gibbs free energy $\left(\mathrm{G}_{\mathrm{chem}}=\mathrm{H}_{\text {mix }}-\mathrm{TS}_{\text {conf }}\right)$.

Both scenarios (equimolar as well as that close to the experimentally obtained chemical composition) show that the high-entropy metal-sublattice diboride solid solution is clearly metastable compared to the individual binaries, see Fig. 8a. However, at temperatures above $500 \mathrm{~K}$ the configurational entropy contribution from the metal-sublattice is overcompensating the mixing enthalpy difference rendering the metastable solid solution (red lines with squares) stable over the individual binaries (black lines with pentagons). These calculations assume the enthalpy of formation to be independent of temperature and only consider configurational contributions to the entropy term.

Furthermore, the decomposition of $(\mathrm{Hf}, \mathrm{Ta}, \mathrm{V}, \mathrm{W}, \mathrm{Zr}) \mathrm{B}_{2}$ into $(\mathrm{Hf}, \mathrm{Ta}, \mathrm{Zr}) \mathrm{B}_{2}$ plus $(\mathrm{V}, \mathrm{W}) \mathrm{B}$ plus $\mathrm{B}$, which is observed by APT, is considered in the calculations. This scenario shows an even lower 
$\mathrm{G}_{\text {chem }}$ with $\mathrm{T}<2000 \mathrm{~K}$ for the equimolar scenario, and with $\mathrm{T}<$ $1250 \mathrm{~K}$ for the experimentally determined composition. The fact that our prediction renders $(\mathrm{Hf}, \mathrm{Ta}, \mathrm{V}, \mathrm{W}, \mathrm{Zr}) \mathrm{B}_{2}$ as more stable than the experimentally verified multi-phase decomposition scenario at the experimentally determined decomposition temperature may be rationalised by considering the above described limitations of the here employed basic computational strategy. For example, we have not treated the temperature dependence of the enthalpies as well as the thermal entropy contributions.

The significantly more negative energy of formation for the multi-phase decomposition scenario $\left[(\mathrm{Hf}, \mathrm{Ta}, \mathrm{Zr}) \mathrm{B}_{2}\right.$ plus $(\mathrm{V}, \mathrm{W}) \mathrm{B}$ plus $\mathrm{B})$; green lines with hexagons in Fig. 8] would suggest that the formation out of $(\mathrm{Hf}, \mathrm{Ta}, \mathrm{V}, \mathrm{W}, \mathrm{Zr}) \mathrm{B}_{2}$ (red lines with cubes in Fig. 8) occurs at quite "low" temperatures (as soon as diffusion is possible); the energy gap (driving force for decomposition) between $(\mathrm{Hf}, \mathrm{Ta}, \mathrm{V}, \mathrm{W}, \mathrm{Zr}) \mathrm{B}_{2}$ and these decomposition products is rather large. But please consider that in solid-solid phase transitions an additional amount of energy, the strain energy, caused by the differences in specific volumes of the phases, has to be overcome. Consequently, the products become steadily more unfavourable with increasing degree of transformation, see Fig. 8b. The decomposition of $(\mathrm{Hf}, \mathrm{Ta}, \mathrm{V}, \mathrm{W}, \mathrm{Zr}) \mathrm{B}_{2}$ towards $(\mathrm{Hf}, \mathrm{Ta}, \mathrm{Zr}) \mathrm{B}_{2}$ plus $(\mathrm{V}, \mathrm{W}) \mathrm{B}$ plus $\mathrm{B}$ causes an increasing strain energy with increasing degree of transformation, retarding or even limiting the process. The equimolar composition would lead to slightly lower retarding energies than the near-to-experimental composition (see dashed and solid green lines with hexagons in Fig. 8b, being $0.035 \mathrm{eV} / \mathrm{at}\left(0.57 \mathrm{~kJ} / \mathrm{cm}^{3}\right.$ or $\mathrm{GPa})$ and $0.038 \mathrm{eV} /$ at $\left(0.65 \mathrm{~kJ} / \mathrm{cm}^{3}\right.$ or $\left.\mathrm{GPa}\right)$, respectively, for a complete transformation. For comparison we also calculated the associated strain energy for a decomposition towards the binary phases, yielding a similar strain energy for the near-to-experimental composition, but higher one for the equimolar composition (black lines with pentagons in Fig. $8 \mathrm{~b}$ ). The balance between driving and retarding energies for the decomposition of the HESB (Fig. 8a and b) is also the reason, why we observe the decomposition not immediately at temperatures where diffusion would be sufficient (in addition to the energy required for the formation of new interfaces [41] and distribution of elements, summarised in nucleation processes).

Detailed XRD studies of powdered free-standing coating material after the individual vacuum-annealing treatments allow drawing a picture of their thermal stability and decomposition processes, Fig. 9. In the as-deposited state, the pattern clearly shows a single-phase solid solution with $\mathrm{AlB}_{2}$-prototype structure having lattice parameters of $\mathrm{a}=3.09 \AA$ and $\mathrm{c}=3.28 \AA$. Identical values were obtained for the coating grown on sapphire substrates (Fig. 3), but here no preferred growth orientation can be detected as we analysed powdered coating material. The latter is essential to avoid detrimental substrate interference and interactions during annealing at these rather high temperatures up to $1600^{\circ} \mathrm{C}$. The coatings remain single phased up to $\mathrm{T}_{\mathrm{a}}=1300^{\circ} \mathrm{C}$ and also the XRD peak positions and shapes are relatively unaffected, suggesting for constant lattice parameters, macro- and microstresses. The full width at half maximum even slightly increases when increasing $T_{a}$ to $1300^{\circ} \mathrm{C}$, suggesting actually an increased lattice distortion. Only when increasing $T_{a}$ further to $1400^{\circ} \mathrm{C}$ the formation of additional small XRD peaks at diffraction angles of $\sim 30$ and $\sim 33$ deg can be detected, and the widths of the XRD peaks from the remaining matrix decreases. After annealing at even higher temperatures, these small XRD peaks (from the emerging phase) further increase in intensity and additional ones can be detected (see the pattern for $T_{a}=1600^{\circ} \mathrm{C}$ ), from which it was possible to identify the crystal structure. The additional XRD peaks (indicated by blue stars in Fig. 9) suggest the formation of an orthorhombic structure with lattice parameters of $\mathrm{a}=3.16 \AA \mathrm{A}, \mathrm{b}=8.41 \AA$, and $\mathrm{c}=3.06 \AA$. Detailed APT investigations indicate a separation of the high-entropy metal-sublattice (Hf,Ta,V,W,Zr) $\mathrm{B}_{2}$ towards $(\mathrm{Hf}, \mathrm{Ta}, \mathrm{Zr}) \mathrm{B}_{2}$ and $(\mathrm{V}, \mathrm{W}) \mathrm{B}$ upon annealing at $T_{a} \geq 1400^{\circ} \mathrm{C}$. Therefore, we used the WB reference pattern (ICDD 00-006-0541) and adopted the lattice parameter for a solid solution $(\mathrm{V}, \mathrm{W}) \mathrm{B}$, which is in excellent agreement with the additional XRD peaks. Simultaneously with the formation of this new phase, the XRD peak positions of the solid-solution $\mathrm{AlB}_{2}$-structure shift to lower diffraction angles. Based on detailed APT investigations (presented later) we named the remaining matrix (Hf,Ta,Zr) $B_{2}$. The XRD peak positions of this solid solution suggest for lattice parameters of $\mathrm{a}=3.11 \AA$ and $\mathrm{c}=3.39 \AA$ (indicated by half-filled red hexagons in Fig. 9). The interpolated lattice parameters, according to ICDD reference patterns for $\mathrm{HfB}_{2}, \mathrm{TaB}_{2}$, and $\mathrm{ZrB}_{2}$ (using mole fractions relevant for our chemical composition) are with $\mathrm{a}=3.13 \AA$ and $\mathrm{c}=3.41 \AA$ in excellent agreement.

Even after annealing at $1400^{\circ} \mathrm{C}$ - where already first indications for a phase separation of the solid-solution ( $\mathrm{Hf}, \mathrm{Ta}, \mathrm{V}, \mathrm{W}, \mathrm{Zr}) \mathrm{B}_{2}$ could be detected by XRD - the coating (for this study we used a coated sapphire substrate) still shows the dense fine-fibrous growth morphology, very similar to the as-deposited state (compare Figs. 10a and 5a). However, TEM investigations suggest that the microstructural feature (being elongated in growth direction and presumably caused by boron segregation, already present in the as-deposited state) is more distinct after annealing at $1400^{\circ} \mathrm{C}$, see Fig. $10 \mathrm{~b}$ and especially the higher magnification inset.

Spatially-resolved chemical composition analysis at the nanometer scale of powdered free-standing coating material reveals a random distribution of all elements in the as-deposited state, represented by the reconstruction of $\mathrm{W}$ atomic positions in Fig. 11a. Also, after annealing at $1200^{\circ} \mathrm{C}$ the distribution of elements is still random based on the frequency distribution analysis shown in Fig. 11b. The measured distribution of the constitutional elements (data points) is compared to a random, binomial distribution (lines in corresponding colour code). The Pearson correlation coefficients $\mu$ are $<0.1$ for all elements which indicates a random elemental distribution. After annealing at $\mathrm{T}_{\mathrm{a}}=1400^{\circ} \mathrm{C}$ the formation of $\mathrm{W}$-rich regions is evident from the APT data. W-rich regions with $\geq 35$ at\% are indicated by isoconcentration surfaces. These data suggest an elongated formation along the growth direction, where especially column boundaries are preferred sites to easier accommodate evolving strains (see Fig. 8b) and provide higher diffusivities (even spinodal decomposition preferably starts at column boundaries [42]). The proximity histogram of these regions after annealing at $1400^{\circ} \mathrm{C}$, Fig. $11 \mathrm{c}$, reveals that $\mathrm{V}$ as well as Ta are present in the $\mathrm{W}$-rich regions, while $\mathrm{Hf}$ and $\mathrm{Zr}$ are depleted. Further characteristic is that with increasing $\mathrm{W}$ content also the $\mathrm{B}$ content decreases, which indicates that the stoichiometry changes from $\mathrm{MeB}_{2}$ towards $\mathrm{MeB}$ in the $\mathrm{W}$-rich region. Furthermore, a confined $\mathrm{B}$ enrichment is visible at approximately 0 to $-2 \mathrm{~nm}$ (indicated by dashed lines) and hence at the interface between the $\mathrm{W}$-rich region and the matrix.

After annealing at an even higher temperature $\left(T_{a}=1600^{\circ} \mathrm{C}\right)$ decomposition of the (Hf,Ta, $\mathrm{V}, \mathrm{W}, \mathrm{Zr}) \mathrm{B}_{2}$ solid solution is observed by APT in agreement with XRD data. The chemical composition profile in Fig. 12a reveals the formation of $\mathrm{V}$ - and $\mathrm{W}$-rich regions with up to 10 at\% $\mathrm{V}$ and 40 at\% W, while $\mathrm{Hf}$ and $\mathrm{Zr}$ are depleted and Ta is present with approximately 4 at\%. Also evident is that the B concentration decreases from approximately 58 to 46 at\% in the $\mathrm{V}$ - and $\mathrm{W}$-rich regions. The APT-quantified absolute B concentrations are significantly smaller than the average concentrations obtained by ERDA and preferential $B$ retention has been reported for DC magnetron sputtered $\mathrm{ZrB}_{2}$ thin films [43]. Nevertheless, the observed decrease of the $\mathrm{B}$ concentration from the matrix towards the $\mathrm{V}$ - and $\mathrm{W}$-rich region in combination with XRD data (Fig. 9) indicates the formation of $(\mathrm{V}, \mathrm{W}) \mathrm{B}$ with soluted $\mathrm{Ta}$.

Proximity histograms of Hf, Ta, V, W, and $\mathrm{Zr}$ (Fig. 12b-f) after annealing at $1600^{\circ} \mathrm{C}$ reveal the local enrichment of each 
metal and it is evident that also the chemical composition of the $(\mathrm{Hf}, \mathrm{Ta}, \mathrm{V}, \mathrm{W}, \mathrm{Zr}) \mathrm{B}_{2}$ matrix is significantly altered. Interestingly, all of the interface regions are characterized by a confined $B$ enrichment after annealing at $1600^{\circ} \mathrm{C}$ and the corresponding regions are emphasised by dashed lines. Such confined B enrichment has been also observed for the $\mathrm{W}$-rich regions after annealing at $1400^{\circ} \mathrm{C}$, compare Fig. $11 \mathrm{c}$. Based on the combination of ERDA (indicating no B-loss due to annealing at 1400 or $1600^{\circ} \mathrm{C}$, Fig. 6), TEM, and APT data, we can conclude that the decomposition from $(\mathrm{Hf}, \mathrm{Ta}, \mathrm{V}, \mathrm{W}, \mathrm{Zr}) \mathrm{B}_{2}$ towards $(\mathrm{Hf}, \mathrm{Ta}, \mathrm{Zr}) \mathrm{B}_{2}$ plus $(\mathrm{V}, \mathrm{W}) \mathrm{B}$ is accompanied by the formation of a B-rich interface region between these phases. Why $\mathrm{V}$ and $\mathrm{W}$ are concentrated in the monoboride and $\mathrm{Hf}$, Ta, and $\mathrm{Zr}$ basically remain in the diboride can be understood based on the melting points $T_{m}$ of the individual binary borides. $\mathrm{HfB}_{2}, \mathrm{TaB}_{2}$, and $\mathrm{ZrB}_{2}$ have $\mathrm{T}_{\mathrm{m}}$ values between 3400 and $3600 \mathrm{~K}$, but $\mathrm{VB}_{2}$ and $\mathrm{WB}_{2}$ (actually $\mathrm{W}_{2} \mathrm{~B}_{5}$ ) only exhibit a $\mathrm{T}_{\mathrm{m}}$ of $\sim 3000$ and $2638 \mathrm{~K}$, respectively. The monoboride of W exhibits with $\sim 2940 \mathrm{~K}$ actually an even higher melting point than its diboride [21-25].

\section{Summary and conclusions}

Single-phase $\mathrm{AlB}_{2}$-structured diborides with a high-entropy metal-sublattice (HESB), (Hf,Ta,V,W,Zr)B $\mathrm{B}_{2}$, were deposited by nonreactive magnetron sputtering of a powder-metallurgically prepared diboride target composed of $20 \mathrm{~mol} \% \mathrm{HfB}_{2}, \mathrm{TaB}_{2}, \mathrm{VB}_{2}, \mathrm{~W}_{2} \mathrm{~B}_{5}$, and $\mathrm{ZrB}_{2}$. Chemical composition, growth morphology (dense finefibrous), crystal structure $\left(\mathrm{AlB}_{2}\right.$-type) as well as mechanical properties (E $~ 580 \mathrm{GPa}$ and $\mathrm{H} \sim 45 \mathrm{GPa}$ ) are essentially independent on the bias potential ( $U_{\text {bias }}=-40,-60,-80,-100 \mathrm{~V}$ ) used during their preparation (at a substrate temperature of $450^{\circ} \mathrm{C}$ ). The EDS and ERDA obtained B content is with 262 at\% close to $\mathrm{MeB}_{2}$ stoichiometry. The configurational entropy of the metal-sublattice yields $1.53 \cdot \mathrm{R}$ for the prepared $\left(\mathrm{Hf}_{0.25} \mathrm{Ta}_{0.17} \mathrm{~V}_{0.14} \mathrm{~W}_{0.33} \mathrm{Zr}_{0.11}\right) \mathrm{B}_{2}$, classifying it as high-entropy $(>1.5 \cdot \mathrm{R})$ sublattice diboride. $A b$ initio based calculations indicate that the high-entropy metal-sublattice ensures that the synthesised HESB is energetically more stable at $\mathrm{T}>1250 \mathrm{~K}$ than the decomposition products (Hf,Ta,Zr) $\mathrm{B}_{2}$ plus $(\mathrm{V}, \mathrm{W}) \mathrm{B}$ plus $\mathrm{B}$.

Based on XRD studies the coatings remain single-phased $\mathrm{AlB}_{2}$ structured - with essentially the same lattice parameters and microstresses as in the as-deposited state - even when vacuumannealed at temperatures up to $1300^{\circ} \mathrm{C}$. APT indicates that also the distribution of the elements is random in the as-deposited state as well as after vacuum annealing at $\mathrm{T}_{\mathrm{a}}=1200^{\circ} \mathrm{C}$. Only after annealing at higher temperatures $\left(T_{a} \geq 1400^{\circ} \mathrm{C}\right)$ the formation of an additional phase can be detected by XRD, which was indicated by APT to be a $(\mathrm{V}, \mathrm{W}) \mathrm{B}$ monoboride with soluted Ta. The remaining matrix appears to be an $\mathrm{AlB}_{2}$-structured $(\mathrm{Hf}, \mathrm{Ta}, \mathrm{Zr}) \mathrm{B}_{2}$ (with soluted $\mathrm{V}$ and $\mathrm{W}$ ). Additionally, as the overall boron content is constant over the annealing temperature, the formation of confined B-enriched regions during decomposition takes place. Due to this decomposition the indentation modulus and hardness of $(\mathrm{Hf}, \mathrm{Ta}, \mathrm{V}, \mathrm{W}, \mathrm{Zr}) \mathrm{B}_{2}$ decreased to $\sim 570 \mathrm{GPa}$ and $\sim 40 \mathrm{GPa}$, respectively, when annealed at 1500 and $1600^{\circ} \mathrm{C}$. The probably rather small volume fraction of the newly-formed $\mathrm{W}$-rich regions with $\mathrm{T}_{\mathrm{a}}=1400^{\circ} \mathrm{C}$ has almost no influence on the mechanical properties, which are still very high with $\mathrm{E} \sim 610 \mathrm{GPa}$ and $\mathrm{H} \sim 44 \mathrm{GPa}$.

Based on our results we can conclude that $(\mathrm{Hf}, \mathrm{Ta}, \mathrm{V}, \mathrm{W}, \mathrm{Zr}) \mathrm{B}_{2}$ coatings are superior to constituting diborides on account of their thermal stability and maintained mechanical properties. The random distribution of many different-sized metal species (resulting in a high-entropy metal-sublattice) guarantees for a maintained severe lattice distortion and consequently high microstresses even when annealed at $1300^{\circ} \mathrm{C}$, allowing for the exceptional high hardness.

\section{Declaration of Competing Interest}

The authors declare that they have no known competing financial interests or personal relationships that could have appeared to influence the work reported in this paper.

The authors declare the following

\section{Acknowledgments}

This work was partly funded by the Austrian COMET Program (project K2 XTribology, no. 849109 and project K2 InTribology, no. 872176). The authors acknowledge the use of the X-ray center (XRC) and USTEM at TU Wien. They are also very grateful to Tomasz Wojcik (TU Wien, Austria) for assistance with TEM investigations and valuable discussions. Helmut Böhm (TU Wien, Austria) is acknowledged for assistance with the calculations of the strain energy. Support by the Swedish research council (Contract No. 821-2012-5144) and the Swedish Foundation for Strategic Research (Contract No. RIF14-0053) supporting accelerator operation is gratefully acknowledged. Plansee Composite Materials $\mathrm{GmbH}$ is acknowledged for support with target materials. J.M.S. acknowledges funding from the German research foundation (DFG) within the priority program SPP 2006 CCA-HEA.

\section{References}

[1] B. Cantor, I.T.H. Chang, P. Knight, A.J.B. Vincent, Microstructural development in equiatomic multicomponent alloys, Mater. Sci. Eng. A 375-377 (2004) 213-218, doi:10.1016/j.msea.2003.10.257.

[2] J.-W. Yeh, S.-K. Chen, S.-J. Lin, J.-Y. Gan, T.-S. Chin, T.-T. Shun, C.-H. Tsau, S.Y. Chang, Nanostructured High-Entropy Alloys With Multiple Principal Elements: Novel Alloy Design Concepts And Outcomes, Adv. Eng. Mater 6 (2004) 299-303, doi:10.1002/adem.200300567.

[3] B.S. Murty, J.W. Yeh, S. Ranganathan, High Entropy Alloys, Elsevier, 2014 doi:10.1016/B978-0-12-800251-3.00002-X.

[4] A. Kirnbauer, A. Kretschmer, C.M. Koller, T. Wojcik, V. Paneta, M. Hans J.M. Schneider, P. Polcik, P.H. Mayrhofer, Mechanical properties and therma stability of reactively sputtered multi-principal-metal Hf-Ta-Ti-V-Zr nitrides, Surf. Coat. Technol. 389 (2020) 125674, doi:10.1016/j.surfcoat.2020.125674.

[5] J. Gild, Y. Zhang, T. Harrington, S. Jiang, T. Hu, M.C. Quinn, W.M. Mellor N. Zhou, K. Vecchio, J. Luo, High-Entropy Metal Diborides, A new class of highentropy materials and a new type of ultrahigh temperature ceramics, Sci. Rep. 6 (2016) 2-11, doi:10.1038/srep37946.

[6] Y. Zhang, W.M. Guo, Z. Bin Jiang, Q.Q. Zhu, S.K. Sun, Y. You, K. Plucknett, H.T. Lin, Dense high-entropy boride ceramics with ultra-high hardness, Scr. Mater. 164 (2019) 135-139, doi:10.1016/j.scriptamat.2019.01.021.

[7] G. Anand, A.P. Wynn, C.M. Handley, C.L. Freeman, Phase stability and distortion in high-entropy oxides, Acta Mater. 146 (2018) 119-125, doi:10.1016/j.actamat. 2017.12.037.

[8] A. Sarkar, Q. Wang, A. Schiele, M.R. Chellali, S.S. Bhattacharya, D. Wang, T. Brezesinski, H. Hahn, L. Velasco, B. Breitung, High-entropy oxides: fundamental aspects and electrochemical properties, Adv. Mater. (2019) 1806236 doi:10.1002/adma.201806236.

[9] A. Sarkar, R. Djenadic, D. Wang, C. Hein, R. Kautenburger, O. Clemens, H. Hahn, Rare earth and transition metal based entropy stabilised perovskite type oxides, J. Eur. Ceram. Soc. 38 (2018) 2318-2327, doi:10.1016/j.jeurceramsoc.2017. 12.058.

[10] T.J. Harrington, J. Gild, P. Sarker, C. Toher, C.M. Rost, O.F. Dippo, C. McElfresh, K. Kaufmann, E. Marin, L. Borowski, P.E. Hopkins, J. Luo, S. Curtarolo D.W. Brenner, K.S. Vecchio, Phase stability and mechanical properties of novel high entropy transition metal carbides, Acta Mater. 166 (2019) 271-280, doi:10. 1016/j.actamat.2018.12.054

[11] P. Sarker, T. Harrington, C. Toher, C. Oses, M. Samiee, J.P. Maria, D.W. Brenner, K.S. Vecchio, S. Curtarolo, High-entropy high-hardness metal carbides discovered by entropy descriptors, Nat. Commun. 9 (2018) 1-10, doi:10.1038/ s41467-018-07160-7.

[12] C.-H. Lai, M.-H. Tsai, S.-J. Lin, J. Yeh, Influence of substrate temperature on structure and mechanical, properties of multi-element (AICrTaTiZr) N coatings 201 (2007) 6993-6998, doi:10.1016/j.surfcoat.2007.01.001.

[13] C.-H. Lai, S.-J. Lin, J.-W. Yeh, A. Davison, Effect of substrate bias on the structure and properties of multi-element (AlCrTaTiZr)N coatings, J. Phys. D. Appl. Phys. 39 (2006) 4628-4633, doi:10.1088/0022-3727/39/21/019.

[14] C.H. Lai, S.J. Lin, J.W. Yeh, S.Y. Chang, Preparation and characterization of AlCrTaTiZr multi-element nitride coatings, Surf. Coat. Technol. 201 (2006) 32753280, doi:10.1016/j.surfcoat.2006.06.048.

[15] S.Y. Chang, M.K. Chen, D.S. Chen, Multiprincipal-element AlCrTaTiZr-nitride nanocomposite film of extremely high thermal stability as diffusion barrier for Cu metallization, J. Electrochem. Soc. (2009) 156, doi:10.1149/1.3097186. 
[16] A. Kirnbauer, C. Spadt, C.M. Koller, S. Kolozsvári, P.H. Mayrhofer, High-entropy oxide thin films based on Al-Cr-Nb-Ta-Ti, Vacuum 168 (2019) 108850, doi:10. 1016/j.vacuum.2019.108850.

[17] P.H. Mayrhofer, A. Kirnbauer, P. Ertelthaler, C.M. Koller, High-entropy ceramic thin films; A case study on transition metal diborides, Scr. Mater. 149 (2018) 93-97, doi:10.1016/j.scriptamat.2018.02.008.

[18] V. Moraes, C. Fuger, V. Paneta, D. Primetzhofer, P. Polcik, H. Bolvardi, M. Arndt, H. Riedl, P.H. Mayrhofer, Substoichiometry and tantalum dependent thermal stability of $\alpha$-structured W-Ta-B thin films, Scr. Mater. 155 (2018) 5-10, doi:10. 1016/j.scriptamat.2018.06.005.

[19] V. Moraes, L. Zauner, T. Wojcik, M. Arndt, P. Polcik, H. Riedl, P.H. Mayrhofer, Thermally stable superhard diborides: an ab initio guided case study for VW-diboride thin films, Acta Mater. 186 (2020) 487-493, doi:10.1016/j.actamat. 2020.01.014.

[20] C. Fuger, V. Moraes, R. Hahn, H. Bolvardi, P. Polcik, H. Riedl, P.H. Mayrhofer, Influence of Tantalum on phase stability and mechanical properties of WB2, MRS Commun. 9 (2019) 375-380, doi:10.1557/mrc.2019.5.

[21] P. Villars, H. Okamoto, eds., B-Hf Binary Phase Diagram 0-100 at\% Hf: Datasheet from "PAULING FILE Multinaries Edition - 2012" in SpringerMaterials (https://materials.springer.com/isp/phase-diagram/docs/c_0905924),

[22] P. Villars, H. Okamoto, eds., B-Ta Binary Phase Diagram 0-100 at\% Ta: Datasheet from "PAULING FILE Multinaries Edition - 2012" in SpringerMaterials (https: //materials.springer.com/isp/phase-diagram/docs/c_0902231),

[23] P. Villars, H. Okamoto, eds., B-V Binary Phase Diagram 0-100 at\% V: Datasheet from "PAULING FILE Multinaries Edition - 2012" in SpringerMaterials (https: //materials.springer.com/isp/phase-diagram/docs/c_0903210),

[24] P. Villars, H. Okamoto, eds., B-W Binary Phase Diagram 0-100 at\% W: Datasheet from "PAULING FILE Multinaries Edition - 2012" in SpringerMaterials (https: //materials.springer.com/isp/phase-diagram/docs/c_0103126),

[25] P. Villars, H. Okamoto, eds., B-Zr Binary Phase Diagram 0-100 at\% Zr: Datasheet from "PAULING FILE Multinaries Edition - 2012" in SpringerMaterials (https: //materials.springer.com/isp/phase-diagram/docs/c_0907059),

[26] P. Ström, P. Petersson, M. Rubel, G. Possnert, A combined segmented anode gas ionization chamber and time-of-flight detector for heavy ion elastic recoil detection analysis, Rev. Sci. Instrum. (2016) 87, doi:10.1063/1.4963709.

[27] M. Mayer, S. Möller, M. Rubel, A. Widdowson, S. Charisopoulos, T. Ahlgren, E. Alves, G. Apostolopoulos, N.P. Barradas, S. Donnelly, S. Fazinić, K. Heinola, O. Kakuee, H. Khodja, A. Kimura, A. Lagoyannis, M. Li, S. Markelj, M. Mudrinic, P. Petersson, I. Portnykh, D. Primetzhofer, P. Reichart, D. Ridikas, T. Silva, S.M. Gonzalez de Vicente, Y.Q. Wang, Ion beam analysis of fusion plasmafacing materials and components: facilities and research challenges, Nucl. Fusion 60 (2019) 25001, doi:10.1088/1741-4326/ab5817.

[28] W.C. Oliver, G.M. Pharr, An improved technique for determining hardness and elastic modulus using load and displacement sensing indentation experiments, J. Mater. Res. 7 (1992) 1564-1583, doi:10,1557/JMR.1992.1564.

[29] K. Thompson, D. Lawrence, D.J. Larson, J.D. Olson, T.F. Kelly, B. Gorman, In situ site-specific specimen preparation for atom probe tomography, Ultramicroscopy 107 (2007) 131-139, doi:10.1016/j.ultramic.2006.06.008.

[30] G.. Kresse, D. Joubert, From ultrasoft pseudopotentials to the projector augmented-wave method, Phys. Rev. B - Condens. Matter Mater. Phys. 59 (1999) 1758-1775, doi:10.1103/PhysRevB.59.1758.
[31] J.P. Perdew, K. Burke, M. Ernzerhof, Generalized gradient approximation made simple, Phys. Rev. Lett. 77 (1996) 3865-3868, doi:10.1103/PhysRevLett.77.3865.

[32] A. Van de Walle, M. Asta, G. Ceder, The alloy theoretic automated toolkit: A user guide, Calphad 26 (2002) 539-553 Comput. Coupling Phase Diagrams Thermochem, doi:10.1016/S0364-5916(02)80006-2.

[33] R. Yu, J. Zhu, H.Q. Ye, Calculations of single-crystal elastic constants made simple, Comput. Phys. Commun. 181 (2010) 671-675, doi:10.1016/j.cpc.2009. 11.017 .

[34] Titrian, U. Aydin, M. Friák, D. Ma, D. Raabe, J. Neugebauer, Self-consistent scalebridging approach to compute the elasticity of multi-phase polycrystalline materials, 2012. doi:10.1557/opl.201.41.

[35] M. Friák, W.A. Counts, D. Ma, B. Sander, D. Holec, D. Raabe, J. Neugebauer, Theory-guided materials design of multi-phase Ti-Nb alloys with bonematching elastic properties, Materials (Basel) 5 (2012) 1853-1872, doi:10.3390/ ma5101853.

[36] L.F. Zhu, M. Friák, L. Lymperakis, H. Titrian, U. Aydin, A.M. Janus, H.O. Fabritius, A. Ziegler, S. Nikolov, P. Hemzalová, D. Raabe, J. Neugebauer, Ab initio study of single-crystalline and polycrystalline elastic properties of $\mathrm{Mg}$ substituted calcite crystals, J. Mech. Behav. Biomed. Mater. 20 (2013) 296-304, doi:10.1016/j.jmbbm.2013.01.030.

[37] G.J. Dvorak, Y. Benveniste, On transformation strains and uniform fields in multiphase elastic media, Proc. R. Soc. Lond. Ser. A Math. Phys. Sci. 437 (1992) 291-310, doi:10.1098/rspa.1992.0062.

[38] H.J. Böhm, Stress and Strain Fields Due to Multiple Transforming Inhomogeneities, ILSB Rep, 2005

[39] P.H. Mayrhofer, C. Mitterer, J.G. Wen, I. Petrov, J.E. Greene, Thermally induced self-hardening of nanocrystalline Ti-B-N thin films, J. Appl. Phys. (2006) 100, doi: $10.1063 / 1.2222406$

[40] A. Anders, A structure zone diagram including plasma-based deposition and ion etching, Thin Solid Films 518 (2010) 4087-4090, doi:10.1016/j.tsf.2009.10. 145.

[41] P.H. Mayrhofer, L. Hultman, J.M. Schneider, P. Staron, H. Clemens, Spinodal decomposition of cubic Ti1-xAlxN: comparison between experiments and modeling, Zeitschrift Fuer Met. Res. Adv. Technol. 98 (2007) 1054-1059, doi:10.3139/ 146.101570.

[42] R. Rachbauer, S. Massl, E. Stergar, D. Holec, D. Kiener, J. Keckes, J. Patscheider, M. Stiefel, H. Leitner, P.H. Mayrhofer, Decomposition pathways in age hardening of Ti-Al-N films, J. Appl. Phys. (2011) 110, doi:10.1063/1.3610451.

[43] D.L.J. Engberg, L. Tengdelius, H. Högberg, M. Thuvander, L. Hultman, Atom probe tomography field evaporation characteristics and compositional corrections of ZrB2, Mater. Charact. 156 (2019) 109871, doi:10.1016/j.matchar.2019. 109871.

[44] H. Holleck, Binäre und ternäre Carbid- und Nitridsysteme der Obergangsmetalle, in: G. Petzow (Ed.), Materialkundlich-Technische Reihe 6, Gebrüder Borntraeger, Berlin - Stuttgart, 1984, pp. 1-295.

[45] H. Holleck, Material selection for hard coatings, J. Vac. Sci. Technol. A 4 (6) (1986) 2661-2669, doi:10.1116/1.573700. 